\title{
ANÁLISIS SOBRE LA DESERCIÓN EN LA EDUCACIÓN SUPERIOR A DISTANCIA Y VIRTUAL: EL CASO DE LA UNAD - COLOMBIA
}

\author{
Ángel Humberto Facundo Díaz, Ph. D. ${ }^{22}$
}

RESUMEN

La deserción es quizás uno de los fenómenos que más está afectando los sistemas de educación y, en especial, el esfuerzo por elevar los niveles de formación de los recursos humanos para mejorar la competitividad e ingresar plenamente a la sociedad del conocimiento. Por supuesto, Colombia no es la excepción.

Existen diversos enfoques metodológicos para analizar la deserción. En Colombia, el Ministerio de Educación Nacional puso al servicio, en el año 2006, el Sistema SPADIES (Sistema de Prevención y Análisis de la Deserción en las Instituciones de Educación Superior), que toma en consideración la denominada "primera deserción" (first drop out), es decir, el abandono de un programa académico por dos semestres consecutivos, como un servicio de alerta para que las instituciones tomen medidas para evitarla. El presente estudio tuvo en consideración la información disponible en dicho sistema (todavía incompleta, particularmente en instituciones con programas virtuales), pero siguió igualmente la metodología diseñada para el estudio regional, que considera como desertores, luego de un lapso de tiempo suficiente para titularse, a la diferencia entre los inscritos en una cohorte determinada y la sumatoria de los graduados y quienes aún permanecen en la institución.

Palabras clave: deserción, educación a distancia, educación virtual, causas de la deserción, Colombia, Universidad Nacional Abierta y a Distancia - UNAD.

\begin{abstract}
School drop-out is perhaps one of the phenomenons that most affects educational systems and, in particular, the efforts to improve the educational level of human resources in order to increase competitiveness and fully enter the knowledge-based society. Obviously, Colombia is no exception.

Various methodologies exist for analyzing the drop-out phenomenon. In Colombia, the National Education Ministry launched in 2006 the SPADIES system (System for Drop-out Prevention and Analysis in Higher Education Institutions), which considers the so-called first drop-out, i.e. abandoning an academic program during two consecutive semesters, a warning for educational institutions to adopt measures for its prevention. This study not only used

22 Filósofo y sociólogo. Investigador. Actualmente coordina el Proyecto de Doctorado en Gestión de Conocimiento, en la UNAD. El autor agradece la colaboración en el suministro de información a la doctora Gloria Herrera S., Vicerrectora Académica y de Investigación, así como a diversos funcionarios de ese despacho, en particular a Rafael Ramírez, jefe de la Oficina de Registro y Control Académico; Óscar Angarita, Coordinador del Sistema Nacional de Consejería; de Julio García y Myriam Acuña, para la realización de esta investigación.
\end{abstract}


information available from SPADIES (still incomplete, specially in institutions with virtual learning programs), but also a methodology for regional studies which measures desertion as a function of the difference between the number of members of an entering class and the sum of graduates and students who are still enrolled in the institution, after an adequate period for obtaining a degree.

Key words: Drop-out, distance education, virtual education, drop-out causes, Colombia, UNAD (National Open University for Distance Education)

Recibido: 11 de junio de 2009

Aceptado: 23 de octubre de 2009

\section{INTRODUCCIÓN}

La deserción es quizás uno de los fenómenos que más está afectando los sistemas de educación y, en especial, el esfuerzo que hace recursos humanos por elevar los niveles de formación para mejorar la competitividad e ingresar plenamente a la sociedad del conocimiento. Por supuesto, Colombia no es la excepción.

Existen diversos enfoques metodológicos para analizar la deserción. En Colombia, el Ministerio de Educación Nacional puso al servicio, en el año 2006, el Sistema SPADIES (Sistema de Prevención y Análisis de la Deserción en las Instituciones de Educación Superior), que toman en consideración la denominada "primera deserción" (first drop out), es decir, el abandono de un programa académico por dos semestres consecutivos, como un servicio de alerta para que las instituciones emprendan medidas en aras de evitarla. El presente estudio tuvo en cuenta la información disponible en dicho sistema (todavía incompleta, particularmente en instituciones con programas virtuales), pero siguió igualmente la metodología diseñada para el estudio regional, que considera como desertores, luego de un lapso de tiempo suficiente para titularse, a la diferencia entre los inscritos en una cohorte determinada y la sumatoria de los graduados y quienes aún permanecen en la institución.

La investigación se concentra en el análisis de las estadísticas de la deserción, las características de los desertores, las causas o por lo menos factores asociados al abandono estudiantil en la modalidad a distancia y virtual, así como en las recomendaciones expresadas por una amplia muestra de desertores. Debido a la imposibilidad de obtener datos para toda la modalidad a nivel nacional, debió centrarse exclusivamente en el caso de la Universidad Nacional Abierta y a Distancia - UNAD. Sin embargo, por ser la UNAD la institución con la mayor cobertura en la modalidad a distancia y virtual, su información no sólo es fundamental sino que puede ser tomada como indicativa para esta modalidad a nivel del país.

Para efectos de claridad en la presentación y, especialmente de la comprensión a nivel latinoamericano, el estudio se ha dividido en cuatro secciones. Las dos primeras buscan contextualizar el problema: una ofrece un breve panorama de la educación en Colombia, los avances cuantitativos y el problema de la deserción estudiantil; y la otra muestra las características relevantes de los estudiantes de la UNAD, base para establecer análisis 
comparativos con la sub-población de desertores. Las dos últimas presentan los resultados de la investigación: la tercera se concentra en las estadísticas sobre la deserción y la cuarta analiza las características, las causas de la deserción, así como las sugerencias dadas por la muestra de desertores en una encuesta virtual. En cada uno de estos últimos puntos se siguieron las pautas establecidas para el estudio regional latinoamericano.

Como se indica en las consideraciones finales, a manera de conclusión, el fenómeno de la deserción si bien ha venido disminuyendo en el país gracias a las medidas que han entrado en acción, es todavía elevado. En materia de abandono estudiantil, en el caso colombiano de la UNAD no se presentan —en la actualidad - diferencias significativas entre la modalidad a distancia y virtual, y la educación presencial. La encuesta muestra las características de los desertores, así como algunos factores, particularmente institucionales que estarían asociados. Según quienes respondieron la encuesta son debilidades de la práctica de la metodología a distancia y virtual. Sin embargo, si se toman en cuenta las características de los estudiantes y las potencialidades de estas metodologías, en particular de la educación en ambientes digitales, parecen ser uno de los mecanismos más prometedores frente a la elevación masiva del nivel educativo y la utilización del conocimiento como factor de desarrollo social y productivo.

\section{EL PANORAMA EDUCATIVO COLOMBIANO}

\section{Los avances cuantitativos recientes}

En la era actual, el conocimiento es factor fundamental de competitividad y desarrollo. Sin embargo, para poder ingresar a la sociedad del conocimiento se requiere que la población general pueda acceder no sólo a la educación, sino alcanzar los más elevados niveles posibles, tanto en materia de calidad como de una educación superior pertinente.

Si se analizan las tasas históricas de escolaridad, se encuentra que Colombia viene de presentar tasas preocupantemente bajas, no obstante los esfuerzos realizados desde los años sesenta del siglo pasado por expandir la matrícula, cuyo avance fue calificado por Sarmiento y Caro, como lento, insuficiente e inequitativo. Estos avances han fluctuado de forma relativamente concomitante con los vaivenes de la economía. Mientras el crecimiento promedio de los sesenta y setenta fue del 2.2\%, del ochenta al 2000 se contrajo al 1\%. Durante los últimos 50 años del siglo pasado, la tasa de escolaridad de la población colombiana aumentó sólo en 4.4 años, llegando, en el umbral del siglo XXI, la tasa promedio de escolaridad de la población colombiana sólo a 7.3 años de estudio y en la zona rural no alcanzaba los 5 años de primaria que, en ese entonces se identificaba con la educación básica. ${ }^{23}$

Así las cosas, la apertura del país a la globalización y el ingreso a la sociedad de la información y el conocimiento no sólo coincidió con un período de bajo crecimiento económico, sino con un bajo nivel educativo de la población. No obstante los avances, ésta continúa aún en niveles que no superan los promedios regionales.

23 Cfr. Gaviria, Mario Alberto. Capital humano, complementariedades factoriales y crecimiento económico en Colombia. En: Ensayos de economía, ISSN 0121-117X, Vol. 15, No. 27, 2005, Págs. 25-74. 
Así, por ejemplo, en el año 2007, de acuerdo con datos de la UNESCO, mientras en la región latinoamericana los promedios de matrícula de educación básica y media llegaban al 95\%, la tasa colombiana de escolaridad neta alcanzaba el 89,38\% de acuerdo con la información oficial del Ministerio de Educación Nacional, siendo la escolaridad aún más baja en las zonas rurales. Y, en determinadas cohortes de edad, por ejemplo en niños de 3-4 años, cuando el estímulo y el alistamiento son tan necesarios, la escolaridad promedio no superaba el $40 \%$ mientras en el promedio latinoamericano llega al $60 \%$.

\section{El problema de la deserción estudiantil}

Dentro de este panorama la deserción estudiantil en cualquiera de los niveles del sistema educativo colombiano, es decir, el abandono del proceso educativo formal antes de haber culminado el ciclo educativo al cual aspiraba, ha sido y continúa siendo un fenómeno muy elevado. No obstante, las investigaciones sistemáticas al respecto sobre deserción son de reciente data (2003), ${ }^{24}$ así como las estrategias y mecanismos institucionales que —a todos los niveles - han comenzado a implementarse.

La deserción estudiantil, ya sea la periódica (semestral o anual) o por cohortes, es una manifestación de fracaso tanto individual como institucional, ya que afecta la autoestima y el desempeño del estudiante en la sociedad, y evidencia las ineficiencias e inequidades del sistema, en tanto se presenta mayormente entre la población rural y entre los más pobres y — sin lugar a dudas - tiene un impacto negativo sobre los recursos que se invierten en la formación de capital humano, sobre la competitividad, y sobre el desarrollo económico y social.

Las estadísticas educativas de Colombia al respecto son preocupantes. De acuerdo con datos del año 2004, de cada 100 estudiantes que ingresaron a la escuela, sólo 47 lograron terminar bachillerato. De éstos, sólo 27 ingresaron a la educación superior. Y, del escaso número de quienes ingresaron, sólo un poco más de la mitad termino exitosamente sus estudios y se titulo en cualquiera de las modalidades de educación superior (técnica, tecnológica o universitaria).

La deserción ${ }^{25}$ es un fenómeno complejo, cuyos factores deben ser tratados de manera integral. Son diversas las perspectivas desde las cuales se puede analizar la situación: desde la psicológica y sociológica, pasando por la económica, hasta la institucional. Desde el punto de vista de la política educativa (único aspecto al cual se hará referencia en este trabajo), el

24 Cfr. Ministerio de Educación Nacional. Deserción Estudiantil en la Educación Superior colombiana. Elementos para su diagnóstico y tratamiento. Bogotá: MEN, 2008. Pág. 32. Allí se hace un recuento de los principales trabajos.

25 Los teóricos diferencian diversos tipos de deserción: la "primera deserción" (first drop out) o el abandono de la carrera o estudios durante 2 semestres académicos consecutivos; la deserción interna o cambio de programa, sin abandono de la institución; la deserción institucional o abandono de la institución, tanto para continuar estudiando en otra como para dejar los estudios definitivamente; así como una amplia clasificación con relación al momento en que se da (precoz, temprana, tardía); o según el tipo de motivos o factores asociados a ella. Igualmente existen diferentes formas de medición: deserción por períodos (semestral o anual) y por cohortes. Esta última indica el número de estudiantes que se retiró sin lograr concluir el programa o nivel al cual aspiró y en el cual se inscribió en momento dado. Como tal, requiriere de una fecha de corte suficientemente razonable durante la cual se puede terminar el programa o nivel, para realizar el análisis. 
Ministerio de Educación Nacional de Colombia y las instituciones educativas han puesto en marcha las más variadas estrategias y mecanismos en los diversos niveles y atendiendo a los diversos factores asociados con este fenómeno.

Así las cosas, a nivel de educación básica y en relación con el factor económico, uno de los prioritarios que se asocia con la inasistencia escolar y la deserción, se estableció el sistema de capitación y eficiencia en la distribución de los recursos financieros, junto con el programa "ni un solo niño por fuera de la escuela" y otro de subsidios monetarios a las familias de bajos recursos; se han creado nuevos cupos y mejorado la infraestructura física, tecnológica y la disponibilidad de textos en el sector educativo oficial, buscando garantizar la gratuidad de la educación básica; y, en algunas ciudades, se ha creado un moderno sistema de bibliotecas de indudable apoyo a la labor educativa. En materia de normatividad, se racionalizó la planta docente; se modificó el sistema de evaluación académica; se introdujo la denominada promoción automática, así como la promoción (o integración) por ciclos para evitar las dificultades en el paso de un ciclo a otro, y un programa de seguimiento a los alumnos que fallan.

A nivel de educación superior, se han diseñado estrategias y mecanismos relacionados con algunos de los principales factores asociados. Entre otros, la introducción de mejoras en la adaptación de los nuevos estudiantes a la vida universitaria; las consejerías estudiantiles; campañas de planificación familiar; y la prohibición del expendio de licores en zonas aledañas a las instituciones. Entre las principales acciones dirigidas hacia los factores académicos se ha promovido la introducción de programas de orientación profesional; de tutoría; talleres de nivelación y mejoramiento de competencias básicas; foros y mecanismos de divulgación de experiencias exitosas. Un amplio programa de crédito académico focalizado en estudiantes en riesgo, busca superar los factores económicos.

Sin duda, el más novedoso mecanismo ha sido el reciente diseño y puesta en funcionamiento de la mencionada herramienta informática, denominada SPADIES (Sistema de Prevención y Análisis de la Deserción en las Instituciones de Educación Superior), como programa institucional para identificar y hacer seguimiento a los posibles desertores. El sistema toma en consideración la que se denomina como "primera deserción" (first drop out); es decir, a quienes por dos períodos académicos consecutivos no asisten a la institución. No obstante que no todas las instituciones han ingresado aún la información al sistema SPADIES, éste ha comenzado a arrojar importantes resultados no sólo sobre deserción, sino incluso sobre las probabilidades o funciones de supervivencia en cada uno de los cuatro factores y variables consideradas. ${ }^{26}$

Para algunos, las anteriores medidas no están lo suficientemente articuladas en una verdadera política educativa. Con todo, es evidente que, de acuerdo con la información oficial, han tenido resultados positivos. A nivel de educación básica, la cobertura neta subió del 84,39\% en el 2002 al 89,38\% en el 2008, y la deserción se redujo al 5\% anual, de acuerdo con datos de 2003. En este nivel, Colombia se encuentra en un lugar intermedio en la región. Y, en educación

26 Cfr. Ministerio de Educación Nacional, Deserción Estudiantil en la Educación Superior colombiana. Elementos para su diagnóstico y tratamiento. Op. Cit. 
superior, la tasa de cobertura con relación a la cohorte de $18-23$ años subió del 20,5\% en el 2002 al 24,6\% en el 2006, y las tasas de deserción bruta anual, según cálculos de la subdirección de Desarrollo Regional del MEN, ha descendido del $16.5 \%$ en el 2003 al 12.9\% en el 2006, mientras que la deserción general acumulada por cohorte habría bajado del $51.6 \%$ en el 2003 al $47.5 \%$ en el año 2006. Con todo, todavía una y otra tasas de deserción siguen siendo elevadas. Y, no obstante estas últimas cifras se encuentran dentro de los promedios latinoamericanos que oscilan entre $40 \%$ en Argentina y el 59\% en Brasil según datos del IESALC, la deserción educativa general y, en especial, la deserción estudiantil a nivel superior continúa siendo un problema preocupante, y por resolver.

\section{LA UNAD Y LA LUCHA POR LA RETENCIÓN Y EL RENDIMIENTO ACADÉMICO}

La educación superior a distancia ha sido, desde su inicio en los ochenta, para la UNAD, una estrategia de flexibilización de la oferta educativa destinada fundamentalmente a ampliar la cobertura.

Si bien durante las primeras dos décadas de operación de esta modalidad en la mediación postal (nivel I de la educación a distancia) este objetivo no se cumplió al menos de forma significativa, con la introducción de la digitalidad o la denominada educación virtual (nivel III de la educación a distancia), el incremento de la matrícula sí ha llegado a niveles importantes.

Como no todas las instituciones han introducido información al sistema SPADIES, en la actualidad no se dispone aún de información oficial agregada sobre la modalidad a distancia y virtual. Por tal razón, el caso de la Universidad Nacional Abierta y a Distancia - UNAD, la universidad líder y con mayor número de estudiantes en esta modalidad en el país, puede considerarse como una clara referencia al respecto.

\section{Los mecanismos utilizados para garantizar la retención estudiantil}

Dadas las características de los estudiantes de la UNAD (generalmente personas que por razones de promedio académico ${ }^{27}$ o que por razones económicas habían dejado un tiempo de estudiar) así como el desconocimiento de la metodología de aprendizaje autónomo, característico de la educación a distancia, la preocupación por la retención estudiantil y por el rendimiento académico han sido, desde el inicio de los programas de educación a distancia, una preocupación institucional. De hecho, son diversos los mecanismos que se encuentran a lo largo de la historia de la UNAD.

Con todo, en la historia de la institución se diferencian claramente dos grandes períodos: de una parte, el período 1984-2003, durante el cual la UNAD (inicialmente llamada UNISUR) era una institución universitaria dependiente del Ministerio de Educación Nacional y se dedicaba exclusivamente a la educación a distancia "postal" (el denominado nivel I de educación a distancia), con tutorías fundamentalmente presenciales. Y el período 2004 en adelante, en el

27 En Colombia los bachilleres deben presentar el denominado Examen del ICFES que evalúa sus conocimientos y es requisito para el ingreso a las instituciones de educación superior. 
cual, durante la reforma de las entidades del Estado que tuvo lugar a partir del año 2002 y luego de haberse considerado la desaparición formal de la entidad (una propuesta era anexar el sistema de distancia a una universidad establecida), se tomó finalmente la decisión de fortalecer la institución. De hecho, a partir del 2004, se inicia un período de importantes transformaciones.

Uno de los primeros cambios que caracterizan el actual período institucional fue la creación del Sistema Nacional de Consejería, que se inicia precisamente en el 2004. Este sistema es una estrategia que tiene por función el asesoramiento y acompañamiento a los estudiantes, la evaluación de sus competencias para conocer sus dificultades de aprendizaje y ayudarles con estrategias de intervención, estrategias personales de aprendizaje, el diseño de planes de mejoramiento académico, redes colaborativas y programas de bienestar, con el fin de incrementar su motivación, su integración social, académica y cultural, y disminuir el riesgo de deserción. Este último punto era especialmente importante, ya que la incertidumbre temporal creada por la mencionada reforma, fue un factor que suscitó la deserción institucional de un importante número de estudiantes.

Otras importantes trasformaciones fueron: el ingreso de la institución a la educación virtual (nivel III de educación a distancia), cuyos primeros cursos virtuales se ofrecen a partir del 2006 (en la actualidad la totalidad de los programas se ofrecen tanto en mediaciones virtuales como "tradicionales"); y, sin duda alguna, la transformación más significativa, fue alcanzar el reconocimiento como universidad autónoma, que se logró el 16 de agosto de 2006.

Estas características evidencian la existencia de procesos de mejoramiento (incluso la institución ha entrado en la actualidad en el proceso de obtención de la acreditación de alta calidad), que como se verá en las estadísticas han tenido un impacto positivo en materia de retención y del rendimiento académico en relación con el primer período institucional.

Durante el primer período, 1984-2003, existieron diversos mecanismos tendientes a mejorar la retención y el rendimiento académico. Entre otros, el diseño de un nivel introductorio para reforzar en los estudiantes las competencias básicas de ingreso, especialmente de lectoescritura, matemática, y ciencias (física y química), y un seminario de orientación, denominado de "Recontextualización". Este nivel se realizaba en un semestre, previo al ingreso formal a la Universidad. Sin embargo, si bien se lograba el objetivo de mejorar las competencias de entrada de los estudiantes, indirectamente también tuvo como "efecto perverso" que algunos de ellos, una vez fortalecidas sus competencias básicas, abandonaran la institución, antes de ingresar formalmente a estudiar la carrera seleccionada.

Ante tales situaciones, a partir del año 2004, se introducen algunas modificaciones en los anteriores mecanismos. Entre ellas, permitir el ingreso directo de los estudiantes a la carrera escogida, pero durante el primer semestre de estudio, además de tomar algunas materias del respectivo programa, debían tomar un curso denominado "Sistema de Integración UNADISTA", 
que además de dar a conocer los principios institucionales, preparaba a los estudiantes en la metodología de aprendizaje autónomo. Y, con la creación del Sistema Nacional de Consejería, ${ }^{28}$ se inició un trabajo de mayor acompañamiento y asesoría al estudiante. Este mecanismo, que ha enfocado sus mayores esfuerzos en los estudiantes nuevos, pretende ser el eje fundamental para lograr que los más propensos a abandonar sus estudios permanezcan en la Universidad.

Posteriormente, con la introducción en la institución del campus digital para el ofrecimiento de cursos y programas virtuales, en el año 2006 debieron crearse nuevas estrategias y mecanismos con el fin de evitar ésta, como una nueva causa de abandono, ya que este paso fue traumático para un importante número de estudiantes, acostumbrados a la educación a distancia "tradicional", en la cual la presencialidad jugaba todavía un importante rol y, porque al carecer de suficientes medios tecnológicos y de una adecuada capacitación y destrezas digitales, temían el ingreso al mundo virtual, desconocido para muchos de ellos, inclusive para buen número de tutores.

En consecuencia, en el año 2007 se introduce la "Prueba Única de Ingreso", otro mecanismo para asegurar la retención, que es un test con el cual los consejeros buscan caracterizar a los estudiantes y conocer sus competencias básicas (lectoescritura, fundamentación matemática, alfabetización tecnológica, actitud hacia el trabajo grupal) y problemas. Igualmente se introduce el curso virtual de Metodología del Trabajo Académico a Distancia, la elaboración de Planes de Acción Pedagógica para facilitar el seguimiento a las actividades académicas de los estudiantes, (particularmente de los nuevos), en cada una de las materias que cursan, utilizando para ello la información que arroja el aula virtual. Con estos mecanismos, una vez identificado el estudiante con problemas y mayor riesgo de deserción, se alerta a los respectivos tutores, para que ellos y/o los propios consejeros dialoguen al respecto, motiven y ayuden a los estudiantes frente a las dificultades que tengan. Igualmente se tomaron otras medidas de carácter académico, como la creación de los exámenes nacionales para evaluar el rendimiento de los estudiantes. Al analizar el comportamiento de la deserción en cada período, así como los progresos alcanzados, puede apreciarse el influjo de dichos mecanismos.

Finalmente, antes de entrar al objeto del presente ensayo (las estadísticas sobre deserción e indagar sobre las características de los desertores y las causas del abandono de sus estudios), se hace igualmente necesario conocer la caracterización general de los estudiantes de la UNAD, ya que sirve de base para establecer comparaciones y análisis.

\section{Las características de los estudiantes de la UNAD}

Con base en la información del Sistema Nacional de Consejería, en el semestre académico 2008-I, desde el punto de vista demográfico, la composición mayoritaria del estudiantado de la UNAD es femenina (65\%), y prima la población relativamente mayor: el $60 \%$ oscila

28 Este sistema cuenta en la actualidad con un equipo compuesto por 83 funcionarios, y se encuentra presente en todos los CEAD y CERES de la institución. 
entre los 21 y los 35 años, y el 20\% tiene más de 36 años, hecho que implica que han tenido amplios períodos de interrupción en su proceso de estudio. Sólo el $9 \%$ parece haber ingresado directamente luego de terminar su formación básica y obtener el bachillerato. Si se comparan estos datos con el promedio nacional, igualmente los estudiantes de la UNAD se encuentran en una situación que podría denominarse como desventajosa. La edad promedio de ingreso a nivel nacional es de 17 años. ${ }^{29}$ Es decir, ingresan a las instituciones de educación superior, recién terminan su bachillerato, y el rango promedio de edad de los estudiantes se encuentra entre los 17-22 años.

Desde el punto de vista socioeconómico, la inmensa mayoría de los estudiantes de la institución (77\%) proviene de los estratos socioeconómicos más bajos (niveles 0 a 3 ). De ellos el $24 \%$ pertenece a los niveles 0 y 1 y el $20 \%$ a grupos vulnerables: indígenas y población desplazada. El 42\% proviene de familias en condición de pobreza, es decir que devengan menos de un salario mínimo (aprox. US \$200) y el 39\% entre 1 y 2 salarios mínimos.

Al comparar a los estudiantes de la UNAD con los del resto del sistema de educación superior en términos socioeconómicos, se aprecia una diferencia significativa: las condiciones de los estudiantes de la UNAD son mucho más precarias. En efecto, de acuerdo con cálculos del CEDE, el 32\% de los estudiantes de educación superior provenía de familias con ingresos entre 1 y 2 salarios mínimos; el 49\% entre 2 y 5 salarios mínimos, el $16 \%$ entre 5 y 10 salarios mínimos y el $4 \%$ con salarios superiores a 10 salarios mínimos. ${ }^{30}$ Hay otros dos hechos significativos: de una parte, la inmensa mayoría del estudiantado de la UNAD (73\%) está compuesta por trabajadores con vinculación laboral.

Por otra parte, un tercio de población estudiantil (33\%) por ser casados, vivir en unión libre, ser separados o viudos, tienen responsabilidades familiares adicionales. En cambio, sólo el $8.4 \%$ de los estudiantes a nivel nacional (dentro de los cuales se encuentran igualmente los estudiantes de la UNAD) trabajan y estudian simultáneamente con sus estudios, y el $91.6 \%$ no son trabajadores, es decir, su ocupación central es estudiar. ${ }^{31}$

Al indagarse por el motivo de ingreso a la UNAD, las respuestas son variadas. Sin embargo, prima el que la metodología permite programar el tiempo y se brindan facilidades para estudiar (32\% y 10\%, respectivamente), seguidas por el bajo costo de las matrículas (19\%) y por la calidad educativa $(18 \%)$.

Otra característica importante es el hecho que un buen número de estudiantes prefiere estudiar directamente en las sedes de la Universidad (22\%) y en la biblioteca de la misma (5\%), probablemente por las facilidades locativas y tecnológicas que brindan (de las cuales

29 Ibídem

30 Ministerio de Educación Nacional. Análisis de determinantes de la deserción en la educación superior colombiana con base en el spadies. Primera parte: Factores Socioeconómicos. Factores Académicos e institucionales. Bogotá: Ministerio de Educación Nacional, 2008.

31 Ibídem. 
seguramente carece en su hogar o en el trabajo) e incluso por razones de socialización con sus compañeros.

Para entender esta preferencia, valga advertir que desde el 2006, en la UNAD existen diversas mediaciones: la educación a distancia "tradicional", la virtual exclusivamente, y la inscripción combinada de cursos en ambas modalidades. Así por ejemplo, en el año 2009 de 49.898 alumnos matriculados, $7.648(15.33 \%)$ se inscribió en la modalidad tradicional (aquella que cuenta con tutorías y exámenes presenciales), 15.577 (31.22\%) en la modalidad virtual y 26.673 combinan cursos en las dos modalidades. Sin embargo, y aunque es creciente la tendencia a la virtualidad (los cálculos indican que la matrícula en cursos virtuales se aproxima al $60 \%{ }^{32}$ ), todavía un importante número de estudiantes prefiere seguir o todos o al menos algunos cursos en la metodología "tradicional", ya que no disponen de equipos de cómputo o de buena conectividad o el precio de conexión es elevado.

El hecho relevante del conjunto de estas características es que evidencia claramente que la población estudiantil de la institución se encuentra en condiciones socioeconómicas y académicas desventajosas y, por consiguiente, sería de esperarse que se dieran niveles de deserción significativamente superiores al promedio nacional y a quienes estudian en la modalidad presencial.

\section{LAS ESTADÍSTICAS DE DESERCIÓN EN LA UNAD}

Las estadísticas sobre deserción estudiantil en la UNAD difieren claramente en cada uno de los períodos anotados.

La información sobre deserción es procesada por la Vicerrectoría Académica y de Investigación por medio de la Oficina de Registro y Control Académico y de algunos asesores. Antes de proporcionar los datos, se hace necesario igualmente relevar las diversas etapas por las cuales ha pasado este proceso, ya que explican las dificultades para la obtención, depuración y procesamiento de la información, particularmente la correspondiente a los primeros años de funcionamiento de la entidad. Durante los primeros cinco años, el registro se hizo manual. Posteriormente, se han utilizado dos aplicativos digitales. Entre el año 1989-2005, se utilizó el SIRA (Sistema de Información de Registro y Control Académico), que fue un sistema mono-usuario, instalado en cada uno de los 57 centros donde opera la institución (los denominados CEAD y/o CERES), y la compilación de dicha información se realizaba por medio de backups, con baja velocidad de respuesta. A partir del 2006, la institución utiliza el sistema E-dunat (un aplicativo propietario en línea, que permite el registro y control en tiempo real). La información institucional es proporcionada al sistema SNIES (Sistema Nacional de Información de la Educación Superior) del Ministerio de Educación Nacional, y en la actualidad la información se encuentra en proceso de depuración para proporcionarla igualmente al SPADIES (el sistema de prevención de la deserción).

32 Dato suministrado por la Vicerrectoría Académica y de Investigación de la UNAD. 
Los cálculos realizados por la Oficina de Registro y Control Académico, siguiendo la conceptualización de considerar posible desertor a quien abandona la actividad académica por dos semestres consecutivos (la que sigue el sistema SPADIES del Ministerio de Educación Nacional), indican que el comportamiento de la deserción estudiantil de la UNAD ha sido históricamente superior a la del resto del país. Con todo, ha habido un decrecimiento constante, que se acentúa a partir del 2003 (Ver Gráfico 1).

Gráfico 1. UNAD. Histórico en relación con la denominada "primera deserción”.

(Dos semestres consecutivos de abandono) 1999-I a 2007-2

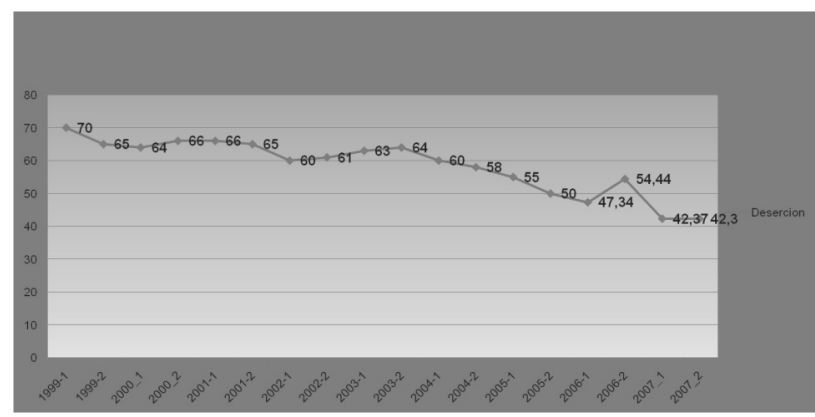

Fuente: unAD. Oficina de Registro y Control Académico.

Al comparar las cifras del último período (luego de la entrada en vigencia de los mecanismos anotados), se puede apreciar que la deserción en la UNAD se comporta de una manera muy semejante a la del resto del país, no obstante las diferencias en la caracterización de los estudiantes, antes anotadas (ver cuadro 1.)

Cuadro 1. Comparación UNAD - país en relación con la denominada "primera deserción" (abandono por dos semestres consecutivos) 2003 -2007

\begin{tabular}{|l|r|r|r|r|r|}
\hline & \multicolumn{1}{|c|}{$\mathbf{2 0 0 3}$} & \multicolumn{1}{c|}{$\mathbf{2 0 0 4}$} & \multicolumn{1}{c|}{$\mathbf{2 0 0 5}$} & \multicolumn{1}{c|}{$\mathbf{2 0 0 6}$} & \multicolumn{1}{c|}{$\mathbf{2 0 0 7}$} \\
\hline País & 51.6 & 50.2 & 48.4 & 47.5 & 40.0 \\
\hline UNAD & 62,0 & 59.0 & 52.0 & 51.0 & 42.3 \\
\hline
\end{tabular}

Fuente: Proyecto "Estrategias para disminuir la deserción en Educación Superior". Subdirección de Desarrollo Sectorial de la Educación Superior. Vice ministerio de Educación Superior. Bogotá, enero de 2007.

Debe, sin embargo, advertirse que, a diferencia de la educación presencial, en la UNAD, por tratarse de un sistema de educación abierta, los estudiantes pueden reintegrarse y continuar sus estudios en cualquier momento, por lo que este tipo de medición (deserción temprana) no necesariamente indica una deserción definitiva.

Para realizar un cálculo de deserción que podría calificarse con mayor propiedad como "abandono definitivo", el estudio regional del cual hace parte este ensayo, diseñó otra 
metodología. Para este estudio, la deserción se define como la diferencia entre el número de estudiantes que ingresaron en un determinado período académico, menos la sumatoria de los graduados y quienes aún permanecen en la institución. Como ya se mencionó, este tipo de cálculo permite un seguimiento de los estudiantes, uno a uno, durante un período razonable de tiempo para haber avanzado y terminado sus estudios. Como cohorte a comparar en los diversos países de la región, se propuso la cohorte de estudiantes que ingresó en el primer período académico del año 2001 (cohorte 2001-I), ya que permitía realizar un seguimiento durante nueve años, tiempo más que suficiente para que los diversos tipos de estudiantes y ritmos de avance académico, pudieran obtener el grado al que aspiraban.

Debe advertirse que, en el caso de la UNAD, esta cohorte hacía relación a uno de los momentos más difíciles de la institución en términos de deserción y no refleja el impacto de las estrategias iniciadas a partir del año 2004 y los mejoramientos posteriores en materia de retención.

Al analizar la corte 2001-I, a la cual ingresaron 6.011 estudiantes, se encontró que, luego de nueve años, se han graduado 1.432 estudiantes (el 23.82\%) y permanecen aún en la institución 321 (el 5.34\% de los estudiantes de la cohorte). Es decir que, al realizar el corte para el análisis en el año 2008, la deserción de esta cohorte fue de $70.84 \%$, dato por demás elevado. (Ver Cuadro 2.)

Cuadro 2. Universidad Nacional Abierta Y A Distancia (UNAD).

Titulados y desertores cohorte de estudiantes 2001-I

\begin{tabular}{|c|c|c|c|c|c|c|c|c|c|c|c|}
\hline & $\begin{array}{c}\text { A } \\
\text { Número de } \\
\text { estudiantes } \\
\text { de la cohorte } \\
\text { de ingreso en } \\
\text { el año 2001-I }\end{array}$ & $\begin{array}{c}\text { B } \\
\text { Número de } \\
\text { Titulados en } \\
\text { el año 2003 }\end{array}$ & 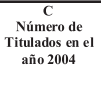 & $\begin{array}{c}\text { D } \\
\text { Número de } \\
\text { Titulados en el } \\
\text { año } 2005\end{array}$ & 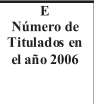 & $\begin{array}{c}\text { F } \\
\text { Número de } \\
\text { Titulados en } \\
\text { el año } 2007\end{array}$ & 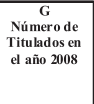 & $\begin{array}{c}\text { H } \\
\text { Número } \\
\text { de Titulados en } \\
\text { el año } 2009\end{array}$ & $\begin{array}{c}\mathbf{I} \\
\text { Total de } \\
\text { Titulados } \\
\\
\mathbf{I}=(\mathbf{B}+\mathbf{C}+\mathbf{D}+ \\
\mathbf{E}+\mathbf{F}+\mathbf{G}+\mathbf{H})\end{array}$ & $\begin{array}{c}\text { J } \\
\text { Número de } \\
\text { estudiantes que } \\
\text { aún permanece } \\
\text { en la Universidad }\end{array}$ & $\begin{array}{c}\mathbf{K} \\
\begin{array}{c}\text { Total de } \\
\text { Desertores }\end{array} \\
\mathbf{K}=(\mathbf{A}-\mathbf{I})-\mathbf{J}\end{array}$ \\
\hline TOTAL & 6.011 & 27 & 8 & 218 & 459 & 487 & 233 & 0 & 1.432 & 321 & 4.258 \\
\hline $\begin{array}{l}\text { TOTAL } \\
\text { (Porcentaje) }\end{array}$ & $100 \%$ & $0,45 \%$ & $0,13 \%$ & $3,63 \%$ & $7,64 \%$ & $8,12 \%$ & $3,88 \%$ & $0 \%$ & $23,82 \%$ & $5,34 \%$ & $70,84 \%$ \\
\hline Semestre I & 6.011 & 24 & 6 & 93 & 175 & 261 & 106 & 0 & 665 & - & \\
\hline Semestre II & $\mathrm{n} / \mathrm{a}$ & 3 & 2 & 125 & 284 & 226 & 127 & 0 & 767 & & \\
\hline $\begin{array}{l}\text { Téenicos y } \\
\text { Tecnólogos }\end{array}$ & - & 6 & $\overline{0}$ & 107 & 52 & 25 & 11 & 0 & 197 & - & - \\
\hline Profesionales & & $21^{*}$ & 8 & 111 & 407 & 462 & 222 & 0 & 1.235 & & \\
\hline
\end{tabular}

Nota: Elaboración del autor, con datos suministrados por el Sistema Nacional de Registro y Control Académico de la UNAD. *Los estudiantes titulados en 2003 validaron el nivel de tecnólogo y provenían de instituciones como el centmag (Pasto), el Centro Tecnológico María Goretti (Pasto) o la Universidad de Pamplona.

La diferencia de cinco puntos porcentuales con los cálculos reportados en los de la denominada "primera deserción" (abandono por dos semestres consecutivos), refleja lo anteriormente afirmado: el estudiante puede volver a ingresar $y$, por consiguiente vuelve a ser contabilizado. En consecuencia, los 5 puntos porcentuales de diferencia, bien podrían corresponder con el porcentaje de alumnos que aún permanece en la institución (5.38\%) y que, seguramente, se graduará en los próximos semestres. Si dicho supuesto se cumple, y se toma en consideración este dato, realmente la deserción de la cohorte es de $65.46 \%$, cifra que coincidiría exactamente con el cálculo del Sistema Nacional de Registro y Control Académico, expresado anteriormente.

Fue interés de las autoridades académicas de la UNAD que se visualizara el impacto de las medidas que, en materia de retención, se tomaron desde el 2004. Así las cosas, se tomó en 
consideración la cohorte 2004-I que, si bien el lapso de tiempo para calcular el abandono definitivo utilizando la metodología propuesta en el estudio regional es todavía demasiado estrecho (abarca tan sólo 5 años, lapso en el cual sólo aquellos estudiantes que no han tenido problema académico alguno han logrado graduarse prontamente). Con base en los datos suministrados por el Sistema Nacional de Registro y Control Académico, los siguientes son los resultados para esa cohorte. (Ver Cuadro 3.)

Cuadro 3. Universidad Nacional Abierta y a Distancia - UNAD.

Titulados y desertores. Cohorte de estudiantes 2004-I

\begin{tabular}{|c|c|c|c|c|c|c|c|c|c|}
\hline & $\begin{array}{c}\text { A } \\
\text { Número }\end{array}$ & $\begin{array}{c}\text { B } \\
\text { Número de } \\
\text { Titulados en el } \\
\text { año 2004 }\end{array}$ & $\begin{array}{c}\mathrm{C} \\
\text { Número de } \\
\text { Titulados en el } \\
\text { año 2005 }\end{array}$ & $\begin{array}{c}\text { D } \\
\text { Número de } \\
\text { Titulados en el } \\
\text { año } 2006\end{array}$ & $\begin{array}{c}\mathrm{E} \\
\text { Número de } \\
\text { Titulados en el } \\
\text { año } 2007\end{array}$ & $\begin{array}{c}F \\
\text { Número de } \\
\text { Titulados en el } \\
\text { año 2008 }\end{array}$ & $\begin{array}{c}\mathrm{G} \\
\text { Número de } \\
\text { Titulados en el } \\
\text { año } 2009\end{array}$ & $\begin{array}{c}\mathbf{H} \\
\text { Total de } \\
\text { Titulados } \mathbf{H}= \\
(\mathbf{B}+\mathrm{C}+\mathrm{D}+\mathrm{E}+\mathrm{F}+\mathrm{G})\end{array}$ & $\begin{array}{c}\text { I } \\
\text { Número de } \\
\text { estudiantes que } \\
\text { aun permanece } \\
\text { en la Universidad }\end{array}$ \\
\hline \begin{tabular}{|c|} 
TOTAL \\
\end{tabular} & 7.124 & 0 & 0 & & 284 & 247 & 0 & 538 & $2687^{*}$ \\
\hline $\begin{array}{c}\text { TOTAL } \\
\text { (Porcentaje) }\end{array}$ & $100 \%$ & $0,00 \%$ & $0,00 \%$ & & $3,99 \%$ & $3,47 \%$ & $0,00 \%$ & $7,55 \%$ & $37,72 \%$ \\
\hline Semestre I & 7.124 & 64 & & & 46 & 113 & & 230 & 2687 \\
\hline Semestre II & $\mathrm{n} / \mathrm{a}$ & 0 & 0 & & 238 & 134 & & 372 & $n / a$ \\
\hline
\end{tabular}

Nota: Elaboración del autor con datos suministrados por la Oficina de Registro y Control de la UNAD. Esta cifra incluye 861 Que terminaron sus estudios y se encontraban en proceso de graduación al momento de realizarse el estudio

En él se evidencia que el porcentaje de deserción en la cohorte $2004-\mathrm{I}$ es de $45.3 \%$, lo que muestra un importante avance en relación con las cohortes anteriores. Por ejemplo, con relación a la cohorte 2001-I, la reducción fue de $25.6 \%$, lo que indica claramente que las estrategias y mecanismos que la institución ha puesto en marcha han comenzado a funcionar de manera muy positiva, no obstante que recién en el 2004 entraron en vigencia. Su resultado: la deserción estudiantil en la institución comenzaba a situarse en niveles semejantes a los del resto de la educación superior en Colombia. Hecho que, por lo demás, indica algo muy significativo: no hay mayores diferencias al respecto entre las modalidades a distancia (caso UNAD) y presencial (caso típico del resto del país), y ello no obstante las diferencias en las características de los estudiantes.

Y, si bien en Colombia, tanto en la educación presencial como la educación a distancia, las cifras de deserción son todavía elevadas (aún cerca de uno de cada dos estudiantes no logra terminar exitosamente su aspiración de graduarse), el reto institucional y del país es continuar perfeccionando y buscando nuevos mecanismos que garanticen a todos el derecho de tener y concluir una educación de calidad. Las condiciones del país y la sociedad del conocimiento así lo exigen.

\section{CARACTERÍSTICAS DE LOS DESERTORES, CAUSAS DE LA DESERCIÓN Y SUGERENCIAS}

Para conocer las características de los desertores y las causas de la deserción se aplicó una encuesta virtual que siguió los parámetros establecidos para el estudio regional. Ésta fue entregada y tabulada por medio de una página web que procesa encuestas digitales. 


\section{Características técnicas de la encuesta}

De acuerdo con información suministrada por la Oficina de Registro y Control Académico, se enviaron encuestas a un grupo de más de 500 estudiantes desertores seleccionados al azar y de quienes se disponía de dirección de correo electrónico actualizada. Se conoce positivamente que del total de encuestas enviadas fueron entregadas y recibidas efectivamente 331 . Y, de ese número, hubo un total de 182 respuestas (tamaño de la muestra), número bastante significativo para los análisis. Se trabajó con un intervalo de confianza de $95 \%$.

Con todo, debe advertirse que la muestra no fue diseñada de forma estratificada por carreras, nivel de los estudios o cohortes de ingreso, ya que debido a la disponibilidad de correos electrónicos no había suficientes direcciones de correo en todas las cohortes, sino en los últimos años. Sin embargo, en la muestra de desertores que responden la encuesta se evidencia que hubo estudiantes de buena parte de las carreras que ofrece hasta el presente la UNAD, así como en los diferentes niveles de formación tecnológica, formación universitaria y especialización (el primer nivel de la formación de postgrado).

La mayor concentración de respuestas de la encuesta se da en estudiantes que aspiraban a recibir formación universitaria (73\% de la muestra) proviniendo la mayoría de respuestas de estudiantes desertores de las carreras de Psicología (34 estudiantes que corresponden al 19\% de la muestra), 33 (18\%) de Ingeniería de Sistemas, 31 (17\%) de Administración de Empresas y 13 (7\%) de Ingeniería Electrónica, 5 (3\%) en Zootecnia, 4 (2\%) de Licenciatura en Filosofía, 4 (2\%) en Ingeniería de Alimentos y otras con porcentajes menores. El 25\% de las respuestas provino de estudiantes que aspiraban a obtener una formación tecnológica, siendo 9 respuestas (equivalente al 5\% de la muestra) de estudiantes de Tecnología Industrial, 9 (5\%) de Tecnología en Regencia de Farmacias, 7 (4\%) de Tecnología Comercial y de Negocios, 5 (3\%) de Tecnología Electrónica, 3 (2\%) de Tecnología de Audio, 3 (2\%) en Tecnología de Sistemas y otras tecnologías con porcentajes menores. Hubo solamente 2 respuestas (equivalentes al 2\% de la muestra) provenientes de desertores de Especializaciones. Y, si bien en los primeros años de funcionamiento de la entidad hubo formación técnica profesional, no hubo respuestas provenientes de desertores de este nivel. Estas distribuciones desiguales se corresponden con la distribución general de estudiantes de la institución, donde el mayor número está en carreras profesionales.

\section{Características de los desertores}

En términos generales las características de los desertores que diligenciaron la encuesta se corresponden con las reportadas para el promedio de los estudiantes de la UNAD. Sin embargo, se presentan algunas diferencias de interés para el análisis.

La mayoría de los desertores que responde la encuesta (51\%) eran bachilleres (o normalistas) al momento de ingresar a la institución. Éste es el mínimo requisito de ingreso al sistema de educación superior. Sin embargo, un poco más de la tercera parte $(37 \%)$ habían realizado ya estudios de formación técnica o tecnológica, bien sea en la UNAD o en otra institución de educación superior (esta información no se preguntó) y, al momento de abandonar sus estudios, 
aspiraban alcanzar la formación universitaria. El 11\% eran profesionales universitarios y probablemente aspiraban a una segunda carrera profesional o al nivel de especialización y el 1\% tenía ya nivel de postgrado. (Ver Gráfico 2)

Gráfico 2. Porcentaje de desortores según nivel de estudios al ingreso a la Universidad

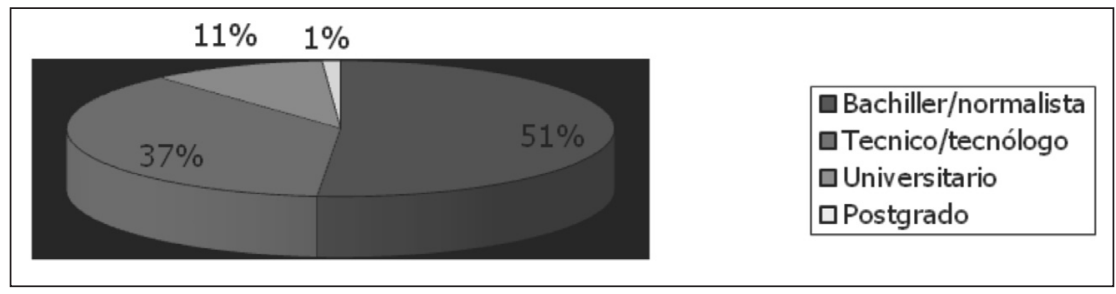

En relación con la distribución por género, de las 182 respuestas recogidas, 97 (el 53\%) fueron respondidas por estudiantes del sexo masculino y 85 (47\%) por mujeres. Este dato no se corresponde con los porcentajes generales de hombres y mujeres que se tienen en la institución. Y, cabe anotar, que tampoco concuerda con la composición por género del país, según la cual y con base en datos del censo general de 2005, a nivel nacional el $51.2 \%$ son mujeres y el $48.8 \%$ son hombres, ni con la distribución por género, existente en las ciudades (las denominadas en el censo como "cabeceras municipales"), donde el $47.7 \%$ son hombres y el $52.3 \%$ son mujeres.

En cambio, la distribución de los desertores de la muestra según la edad al ingreso a la universidad, es congruente con las edades promedio de ingreso de los estudiantes. Además, por la edad se corrobora que la inmensa mayoría de ellos había dejado de estudiar algunos años antes de ingresar a la institución, hecho que es significativo para los análisis sobre deserción. (Ver Gráfico 3)

Gráfico 3. Desertores. Edad al ingresar a la Universidad

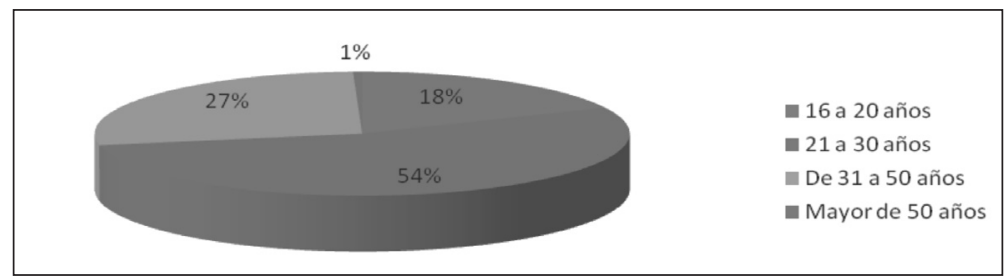

La distribución por cohortes se concentra (como se indicó) en los años más recientes, debido a la circunstancia de disponibilidad de un correo electrónico actualizado. Así las cosas, el $48 \%$ de quienes responden la encuesta habían ingresado a la universidad en el año $2007,22 \%$ en el $2006,13 \%$ en el $2005,6 \%$ en el 2008 y porcentajes menores en años anteriores. Sin embargo, se logró inclusive que el 3\% de las respuestas provinieran de desertores de cohortes anteriores al año 2000. 
Gráfico 4. Desertores. Año de ingreso a al Universiad

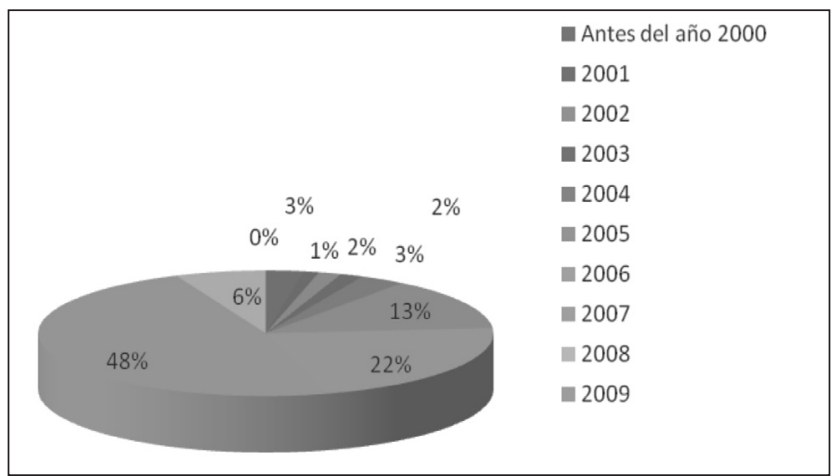

Consecuente con la sobre-representatividad de la encuesta en las cohortes más recientes, la mayoría de los estudiantes aparece retirándose igualmente en estos años, lo que es apenas natural (Ver Gráfico 5). Con todo, esta información es de gran utilidad por cuanto evidencia que no pareciera existir una correlación entre el año de ingreso y de retiro, ni perfilarse una tendencia histórica. De hecho, si establece una proporción entre las dos informaciones (año de retiro vs. ingreso) se encuentra que el año 2008 tiene una razón igual a 3.41; el 2009 a 2.0; el 2007 a 1.0; el 2006 a 0.80; el 2005 a 0,64 y el 2003 a 0.33. En los demás años la razón es igual a cero. Estos datos estarían indicando los "años pico" en materia de deserción, lo que igualmente podría ser de utilidad al correlacionar esta información con los posibles factores que inciden más directamente en el abandono estudiantil.

Gráfico 5. Desertores. Año en que se retiraron de la Universidad

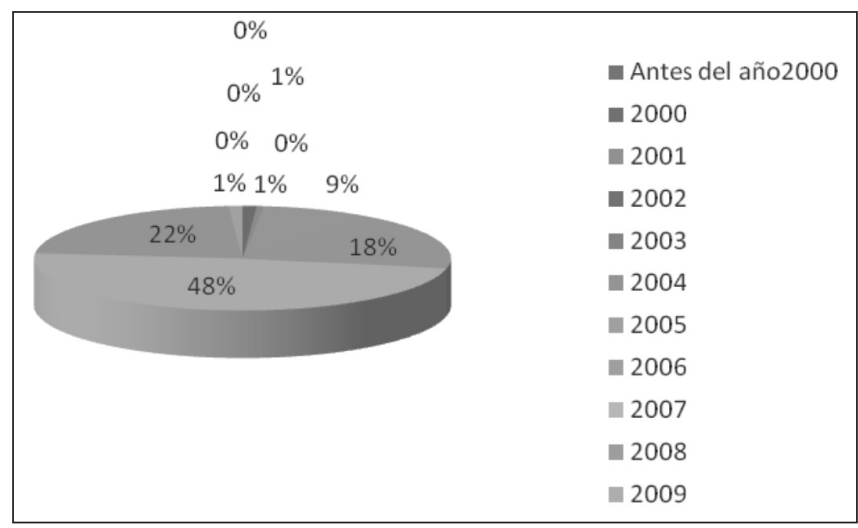

Las características socio-demográficas de la muestra de desertores muestran algunos resultados relativamente sorprendentes con relación a las características generales de los estudiantes la UNAD.

En primer lugar, la mayoría de quienes abandonaron sus estudios(167 estudiantes, que corresponden al 92\%), pertenecían a la zona urbana (cabeceras municipales), mientras que apenas 15 de ellos 
(8\%) a la zona rural. Este dato presenta una cierta correspondencia con la composición urbano/ rural del país. Colombia es una nación mayoritariamente urbana y ha vivido en las últimas décadas un acelerado proceso de urbanización. Sin embargo, según información del Censo General 2005, el 76\% de la población nacional vive en cabeceras municipales (ciudades) y los resultados de la encuesta arrojan que el porcentaje de estudiantes urbanos que se retira de la UNAD es superior a la composición urbana nacional. De acuerdo con los datos disponibles, no se pudo constatar si el porcentaje de estudiantes desertores urbanos se correspondería con un mayor ingreso de estudiantes urbanos a la universidad, y si éste se encuentra igualmente por encima de la proporción nacional.

Al detallar un poco más la anterior información, se observa que la inmensa mayoría (116 estudiantes que corresponden al $63 \%$ de quienes responden la encuesta) vivía en las ciudades más grandes del país: 68 (37\%) vivía en las cuatro ciudades mayores de 1.000 .000 de habitantes, que según el censo general 2005 son: Bogotá, Medellín, Cali y Barranquilla; 48 (26\%) en las ciudades grandes (entre 100.000 y un millón de habitantes, que son 52 ciudades); 23 (13\%) en ciudades medianas (entre 20.000 y 100,000 habitantes) y 43 (24\%) en las ciudades más pequeñas. Este hecho amerita ser destacado, puesto que la UNAD se enfoca prioritariamente hacia las regiones y comunidades de menor desarrollo (generalmente las más menos pobladas).

Si se considera que entre más pequeña la ciudad, por lo general es menor el "alistamiento digital" en materia de número de computadores por habitante, de conectividad, de ancho de banda y de capacitación digital, y los costos de acceso a Internet son más elevados, este dato pareciera no corroborar la hipótesis que con frecuencia se esgrime, según la cual una relativamente "temprana" virtualización de los cursos y programas frente al escaso alistamiento existente en las ciudades y regiones menos desarrolladas del país sería uno de los factores que estarían incidiendo directamente sobre la deserción. (Ver gráfico 6)

Gráfico 6. Desertores según tamaño de la ciudad de residencia

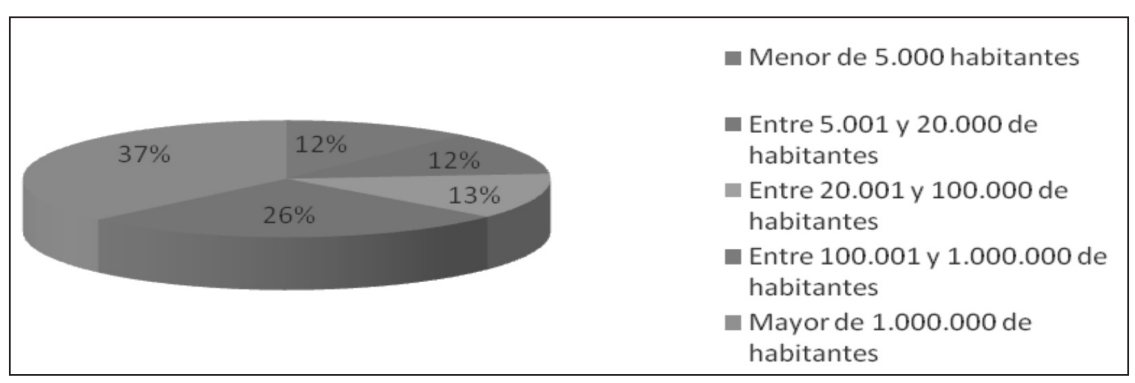

Las características socio-económicas de los desertores concuerdan con las características que se conocen para la generalidad de estudiantes de la institución. El 59\% indicó que trabajaba, el $21 \%$ que tenía recursos propios, el $16 \%$ que dependía de la familia y el $4 \%$ que estaba becado. (Cuadro 3) 
Cuadro 3. Situación económica de los desertores cuando estaban en la Universidad

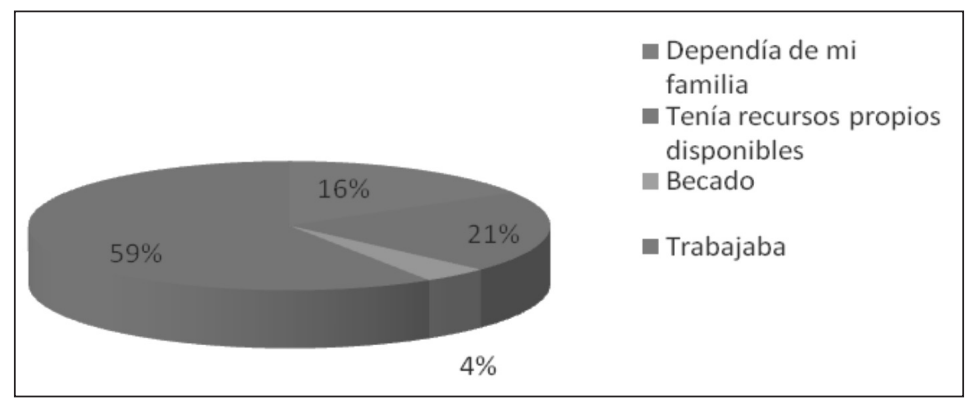

Ahora bien, las jornadas de trabajo que reportan quienes tenían un trabajo remunerado eran bastante intensas: El 62\% trabajaba jornada completa, el 17\% más de media jornada, y el $11 \%$ trabajaba media jornada. Como se verá más adelante, esta característica parece estar asociada y tener un peso importante en las causas del retiro. Pareciera haber cierta incongruencia de éste resultado con el anterior (Cuadro 4). Aparentemente pareciera haber una incongruencia con relación a la pregunta anterior, puesto que en esta última respuesta sólo el 10\% de los desertores indica que no tenía un trabajo remunerado. Sin embargo, no hay tal incongruencia. Lo que parece estar indicando esta respuesta es que el 31\% de diferencia (posiblemente quienes en la pregunta anterior indicaron que disponían de recursos propios, dependían de la familia o estaban becados) posiblemente tenían trabajos no remunerados, por ejemplo, las labores de hogar. Este dato concuerda con las características generales de los estudiantes de la institución, donde hay un relativo alto porcentaje de madres.

Cuadro 4. Desertores. Número de horas semanales de trabajo remunerado cuando desertaron

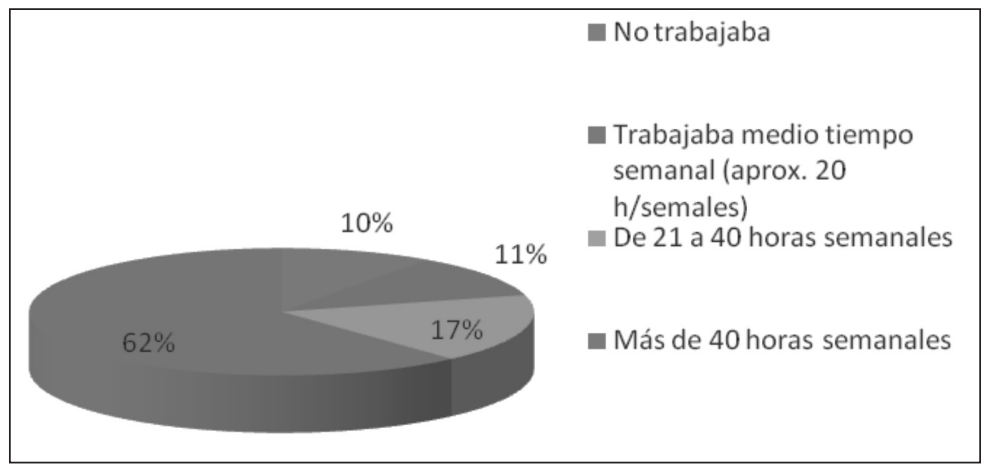

De otro lado, el nivel de ingresos que reportaron los desertores indica que su situación económica era relativamente precaria: 14\% vivían con menos de la mitad de un salario mínimo mensual (menos de US\$100), 15\% con entre medio y un salario mínimo mensual aproximadamente y $25 \%$ entre $\$ 400.000$ y $\$ 600.000$ pesos colombianos. Sin embargo, cerca de la mitad tenían ingresos superiores a $\$ 600.000$ pesos colombianos que equivalen a cerca de US\$300 dólares mensuales (Ver Grafico 7). Si además se tiene en cuenta que un alto 
porcentaje (38\%) estaban casados/vivían en unión libre o eran separados (4\%), la situación económica era para ellos más apretada, debido a las responsabilidades familiares.

Sin embargo, no deja de sorprender que estos datos sean bastante mejores que la situación económica promedio reportada para los estudiantes de la UNAD. Y cabría preguntarse: ¿hay mayores posibilidades de desertar de quienes menos requieren de la institución en términos económicos y pueden acceder a otras opciones de educación? Por ser de interés, ésta fue una pregunta que se hizo indirectamente en la siguiente sección de la encuesta.

Gráfico 7. Nivel de ingresos mesuales de los desertores

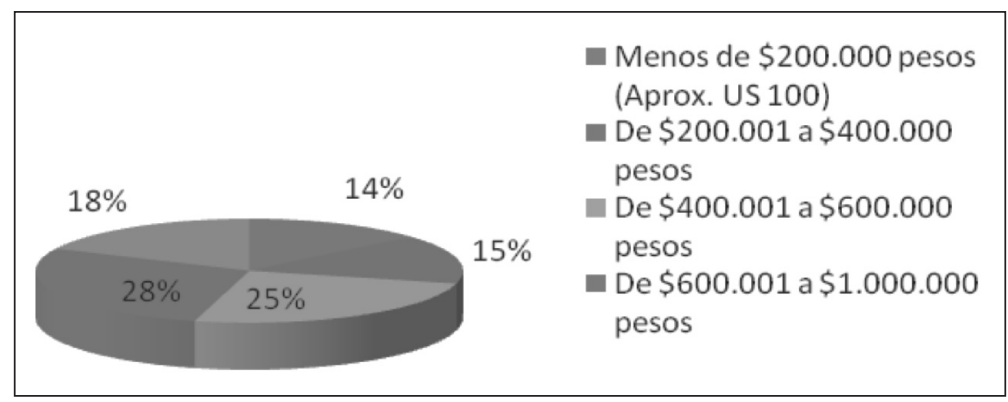

Ahora bien, al indagar en qué semestre de la carrera se retiraron, la inmensa mayoría (87\%) de los desertores lo hizo durante los primeros tres semestres académicos, siendo el de mayor retiro (63\%), el primero (Ver Gráfico 8). Y en esta respuesta sí se puede identificar una clara tendencia: luego del cuarto semestre disminuyen significativamente los retiros. Éste dato podría estar indicando que la situación económica no sería uno de los factores más influyentes, ya que es de suponer que se han realizado mínimos cálculos sobre la sostenibilidad de una carrera que dura entre 3 y 5 años. Además, que los factores que causan un fuerte choque al ingreso a la universidad (entre otros, la interrupción de los estudios antes de su ingreso a la institución o la no adaptación a metodología de la universidad para la gran mayoría desconocida) podrían ser los de mayor incidencia. Y, de todas formas, que la atención prioritaria de la institución debe concentrarse en los primeros semestres, en especial en el primero.

Gráfico 8. Desertores. semestre de abandono de los estudiantes

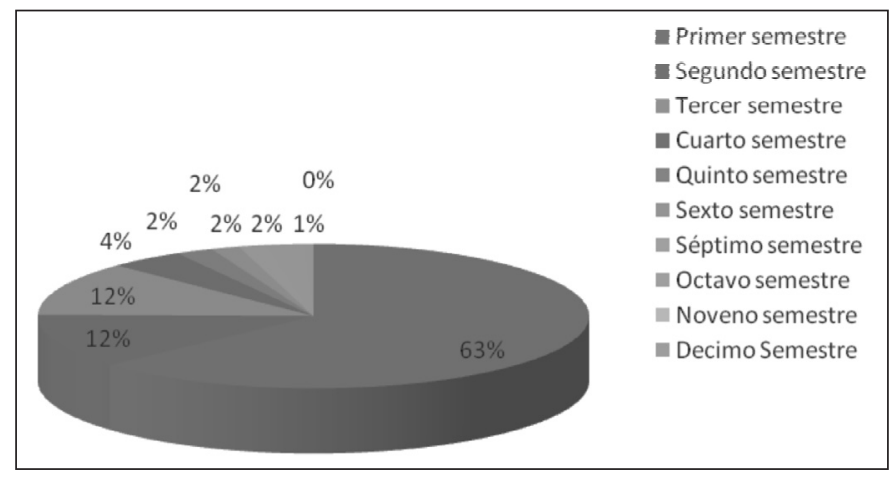




\section{Las causas de la deserción}

Uno de los mayores intereses del estudio consistía directamente en conocer el criterio de quienes habían vivido la situación y las "causas" o al menos los factores asociados con el abandono de sus estudios; si mantenían o habían perdido su aspiración inicial de obtener el nivel académico al que algún día aspiraron; y, en consecuencia, qué acciones sugerían a la Universidad para evitar o disminuir la deserción.

En primer término, se le pidió a los desertores valorar en una escala de Lickert de cinco categorías (deficiente, insuficiente, satisfactorio, bueno y muy bueno) una serie de elementos (o factores) institucionales (12 en total) relativos a la infraestructura, adecuación de los programas, nivel académico de los contenidos, calidad de los docentes (directores y tutores) y la atención de los consejeros y tutores o la metodología de estudio. Igualmente, hacer una valoración sobre algunos factores personales: la adaptación personal a la educación a distancia, la dedicación de tiempo al estudio y el propio desempeño académico. Unos y otros factores eran considerados hipotéticamente como los que podrían haber tenido mayor incidencia sobre el retiro de los estudiantes.

Los resultados al respecto son bastante claros. La mayor parte de los factores institucionales (9 de los 12 preguntados), son valorados en general como satisfactorios o buenos (medias superiores a 3.0). Entre los factores institucionales se valoran como insuficientes o apenas satisfactorios a la orientación y apoyo de los consejeros (media de 2.8), la atención de los tutores (media de 2.9) y los laboratorios (media de 2.9). Y los tres factores personales sometidos a valoración fueron considerados como satisfactorios o buenos (tienen medias superiores a 3-0). Es decir, contrario a lo que se suponía, los desertores concentraron su atención en unos pocos factores.

Digno de destacar es que la principal falencia que identifican los desertores se da en el campo de la inter-relación académica: la orientación y apoyo brindado por los consejeros y la atención de los tutores, si bien la calidad de éstos y de los directores así como la calidad de los contenidos de las materias reciben las más altas valoraciones (medias de 3.3). Es decir, de acuerdo con la percepción de los desertores se dispone de contenidos y docentes de buena calidad, pero se brinda escasa atención al aprendizaje de los estudiantes. En cuanto infraestructura, los laboratorios fueron identificados como otra falencia. Y si bien ninguno de los factores consultados alcanza medias superirores a cuatro y la opción menos escogida es la valoración de "muy buena", la valoración de la atención general de la universidad es satisfactoria, hecho que merece ser destacado. (Ver Cuadro 5.) 
Cuadro 5. Atención general de la Universidad

\begin{tabular}{|c|c|c|c|c|c|c|c|}
\hline Factores & Deficiente & Insuficiente & Satisfactorio & Bueno & $\begin{array}{c}\text { Muy } \\
\text { bueno }\end{array}$ & Media & $\begin{array}{c}\text { Total } \\
\text { RespuestaS }\end{array}$ \\
\hline \multicolumn{8}{|l|}{$\begin{array}{l}\text { Factores } \\
\text { institucionales: }\end{array}$} \\
\hline $\begin{array}{l}\text { La atención general } \\
\text { prestada a usted por la } \\
\text { universidad }\end{array}$ & $11 \%(20)$ & $20 \%(37)$ & $32 \%(59)$ & $27 \%(49)$ & $9 \%(17)$ & 3,0 & (182) \\
\hline El nivel introductorio & $12 \%(21)$ & $23 \%(41)$ & $31 \%(57)$ & $27 \%(49)$ & $8 \%(14)$ & 3,0 & (182) \\
\hline $\begin{array}{l}\text { La orientación y } \\
\text { apoyo brindado por } \\
\text { los consejeros }\end{array}$ & $14 \%(25)$ & $30 \%(54)$ & $25 \%(46)$ & $22 \%(40)$ & $9 \%(17)$ & 2,8 & (182) \\
\hline $\begin{array}{l}\text { La adecuación del } \\
\text { plan y programa } \\
\text { de estudio a sus } \\
\text { expectativas }\end{array}$ & $12 \%(22)$ & $23 \%(41)$ & $31 \%(56)$ & $28 \%(51)$ & $7 \%(12)$ & 2,9 & (182) \\
\hline $\begin{array}{l}\text { El nivel académico de } \\
\text { los contenidos de las } \\
\text { materias }\end{array}$ & $7 \%(12)$ & $14 \%(25)$ & $34 \%(61)$ & $35 \%(64)$ & $11 \%(20)$ & 3,3 & (182) \\
\hline $\begin{array}{l}\text { La pertinencia de los } \\
\text { trabajos y exámenes } \\
\text { con relación al } \\
\text { programa y al nivel en } \\
\text { que estaba }\end{array}$ & $7 \%(13)$ & $19 \%(34)$ & $38 \%(69)$ & $31 \%(56)$ & $5 \%(10)$ & 3,1 & (182) \\
\hline $\begin{array}{l}\text { La calidad de los } \\
\text { docentes (directores, } \\
\text { tutores) }\end{array}$ & $8 \%(14)$ & $14 \%(26)$ & $30 \%(54)$ & $38 \%(69)$ & $10 \%(19)$ & 3,3 & (182) \\
\hline $\begin{array}{l}\text { La evaluación de los } \\
\text { aprendizajes por los } \\
\text { tutores }\end{array}$ & $6 \%(11)$ & $20 \%(37)$ & $32 \%(59)$ & $34 \%(61)$ & $8 \%(14)$ & 3,2 & (182) \\
\hline $\begin{array}{l}\text { La atención de los } \\
\text { tutores }\end{array}$ & $10 \%(19)$ & $29 \%(52)$ & $29 \%(52)$ & $24 \%(44)$ & $8 \%(15)$ & 2,9 & (182) \\
\hline Los laboratorios & $14 \%(25)$ & $24 \%(43)$ & $31 \%(56)$ & $26 \%(48)$ & $5 \%(10)$ & 2,9 & (182) \\
\hline $\begin{array}{l}\text { El servicio de } \\
\text { biblioteca }\end{array}$ & $10 \%(18)$ & $16 \%(30)$ & $32 \%(58)$ & $32 \%(58)$ & $10 \%(18)$ & 3,2 & (182) \\
\hline $\begin{array}{l}\text { El apoyo } \\
\text { administrativo } \\
\text { (inscripción, pago, } \\
\text { certificados...) }\end{array}$ & $15 \%(28)$ & $16 \%(29)$ & $31 \%(56)$ & $29 \%(52)$ & $9 \%(17)$ & 3,0 & (182) \\
\hline \multicolumn{8}{|l|}{ Factores personales: } \\
\hline $\begin{array}{l}\text { Su adaptación a la } \\
\text { educación a distancia }\end{array}$ & $9 \%(17)$ & $26 \%(47)$ & $26 \%(47)$ & $31 \%(56)$ & $8 \%(15)$ & 3,0 & (182) \\
\hline $\begin{array}{l}\text { La dedicación de } \\
\text { tiempo dada por usted } \\
\text { al programa }\end{array}$ & $6 \%(11)$ & $23 \%(41)$ & $30 \%(54)$ & $34 \%(61)$ & $8 \%(15)$ & 3,2 & (182) \\
\hline $\begin{array}{l}\text { Su desempeño } \\
\text { académico }\end{array}$ & $8 \%(15)$ & $20 \%(36)$ & $34 \%(62)$ & $32 \%(58)$ & $6 \%(11)$ & 3,1 & (182) \\
\hline
\end{tabular}


En cambio, al indagarse de forma directa por la razón principal (de más peso) para retirarse de la universidad, las respuestas son variadas. Si bien hay cuatro motivos que sobresalen (razones económicas, descontento con la metodología a distancia, deficiente comunicación, atención y apoyo académico y problemas con la disponibilidad de tiempo), ninguno de ellos alcanza frecuencias superiores al 18\%. Es decir, no hay una causa realmente preponderante.

Con todo, en relación con la valoración anterior, se evidencia una reiteración sobre las deficiencias en la inducción y motivación hacia la metodología a distancia (parte de la función de los consejeros) y sobre la comunicación, atención y apoyo académico (una de las función principales de los tutores), que son factores institucionales. Y sobre la disponibilidad de recursos financieros y de tiempo para dedicar al estudio, que son factores personales (Ver Gráfico 9). Estos datos muestran una gran congruencia en las respuestas.

Gráfico 9. Razón principal (de más peso) para retirarse de la Universidad

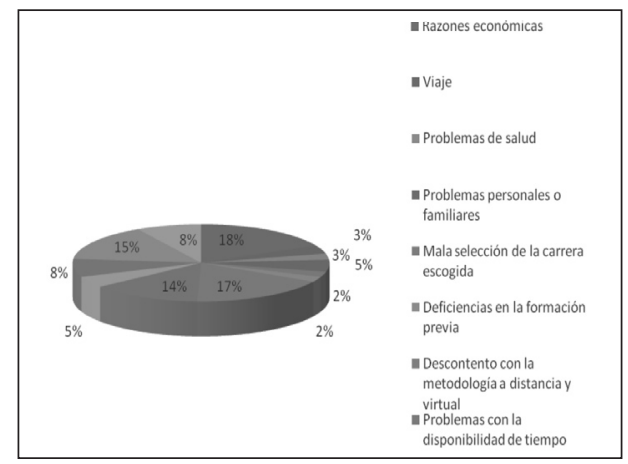

De otro lado, a los desertores se les averiguó si, luego del retiro de la UNAD, habían continuado sus estudios. Solo el 29\% manifiesta haber continuado estudiando. De ellos, el $26 \%$ lo ha hecho en otras instituciones de educación superior y 3\% prosiguió estudios en la misma UNAD, pero en otra carrera. Sin embargo, la inmensa mayoría (71\%) no continuó estudiando. (Ver Gráfico 10.)

Gráfico 10. Desertores. Continuación de sus estudios Universitarios

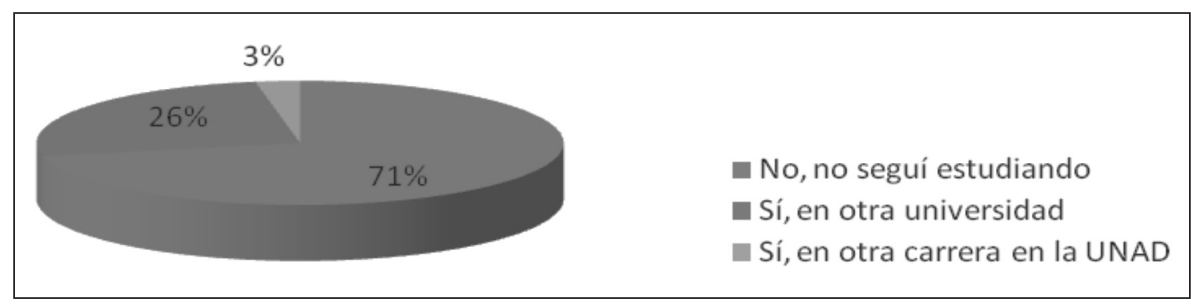

Además, si no estaban estudiando, se les averiguó si tenían intención de volver a hacerlo. Al respecto, es gratamente sorprendente encontrar que la inmensa mayoría (82\%) no ha desistido de su aspiración. Asimismo, es altamente alentador para la UNAD, encontrar que un elevado 
porcentaje (56\%) de quienes desistieron hace un tiempo de sus estudios, manifiestan tener la intención de volver a la institución. Y el 26\% restante piensa continuar estudiando, pero en una universidad presencial (Ver Gráfico 11.)

Gráfico 11. Desortores. Si no continuó estudiando, tiene intención de volver hacerlo?

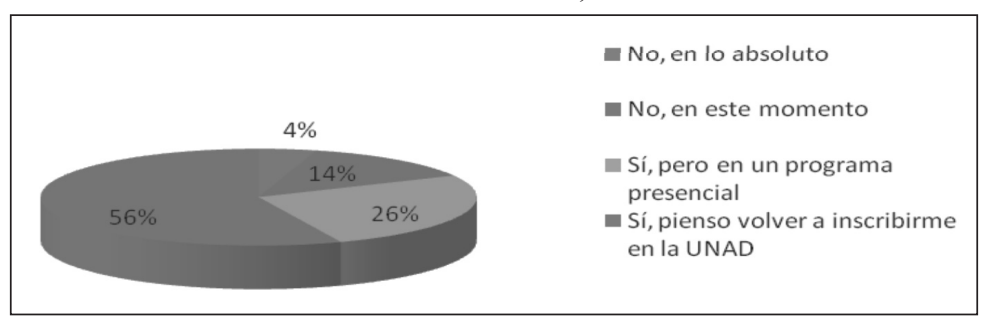

Finalmente, en la encuesta se hizo una única pregunta abierta: ¿Qué mecanismos nos sugiere para ayudar a que los estudiantes no abandonen sus estudios? Al respecto, no sólo fue altamente sorprendente la gran acogida dada en general a la encuesta, sino en particular a esta pregunta específica, que implicaba mayor reflexión, tiempo y una actitud positiva de colaboración, en ocasiones esquiva -por razones de posible resentimiento- en los desertores.

En el elevado número de respuestas a esta pregunta (147 en total) se evidencia lo contrario. Más aún: en cada uno de los formularios hubo más de una sugerencia. Y, todavía más: incluso cuando se cerró la encuesta (y no pudieron responder las otras preguntas del cuestionario), algunos enviaron por correo sus sugerencias. Y, no obstante que su diligenciamiento era anónimo y se tuvo el cuidado que fueran enviados a una firma externa, procesadora de encuestas (tal como se indicó), algunos de quienes respondieron enviaron su nombre indicando que se podía publicar, como forma de ratificar lo dicho.

De otra parte, fue igualmente asombroso el gran reconocimiento que se expresó en varios cuestionarios, por haberlos encuestado. Al respecto, algunas de las frases: "Gracias por permitirme opinar". "Me alegra exponer lo sucedido". "Muchísimas gracias por preocuparse por los desertores". "Muchas gracias por tenerme en cuenta para esta encuesta y ojalá pueda volver a terminar mis estudios". "Gracias por este espacio". "Gracias por tenerme en cuenta". "Gracias". "Gracias". "Gracias". Este es otro hecho digno de mención, pues puede ser objeto de diversas lecturas.

Al analizar detenidamente las respuestas se encuentra que los estudiantes que desertaron tomaron con gran seriedad la tarea. Se nota un alto grado de "inteligencia colectiva" que manifiesta gran sabiduría en el conjunto de sugerencias expresadas. Y, si bien algunas de ellas han sido implementadas ya por la institución, sin lugar a dudas puede afirmarse que aplicar todas ellas implicaría un alto grado de mejoramiento en la calidad del servicio que ofrece la institución.

Por su carácter abierto, no fue tarea sencilla tabular las sugerencias. Para ello, se recurrió a clasificarlas en siete grupos que parecían los más obvios, buscando no repetir las sugerencias. Hecha esta clasificación, se encontró que la mayor concentración de sugerencias para disminuir la deserción se refieren a lo que podría denominarse como mejoras sobre la programación y 
administración académica (con un total de 41 sugerencias relativamente diferentes); luego sobre la tutoría y la labor de los tutores (un total de 33 sugerencias); posteriormente sobre el curso introductorio y la consejería (15 en total); y finalmente sobre la metodología y las tecnologías (11 sugerencias). A estas grupos con mayor frecuencia de respuestas, le siguen otras sugerencias sobre costos y financiación (con 4 en total); sobre laboratorios (con 2); y sobre disponibilidad de tiempo (con 1), aunque éste último fue un aspecto relativamente recurrente, sobre todo cuando hace relación a la dificultad para elaborar trabajos colectivos, y de alguna manera estaba implícito en sugerencias de grupos anteriores.

Aún a sabiendas de que toda clasificación es por naturaleza arbitraria, la concentración que se evidencia en la distribución, indica los temas o áreas que, en opinión de los desertores requieren de mayor atención para evitar, o al menos disminuir, la deserción.

Debe hacerse notar que la mayoría de las sugerencias han sido y son reconocidas por la institución, y varias han sido y son objeto de procesos de mejoramiento. Dada la claridad y precisión de las sugerencias (muy pocas de ellas expresadas como quejas) se presentan a continuación, sin comentarios, y con la única advertencia de que la clasificación y la redacción final dada a las mismas son debidas al autor, quien respetó totalmente el sentido y, en lo posible, la forma en que fueron expresadas. (Ver cuadro 6)

Cuadro 6. Sugerencias expresadas por los desertores para disminuir la deserción, según clasificación del autor:

\begin{tabular}{|c|l|}
\hline \multicolumn{2}{|c|}{ SOBRE LA PROGRAMACIÓN Y ADMINISTRACIÓN ACADÉMICA: } \\
\hline 1. & Mayor organización administrativa y en el registro académico. \\
\hline 2. & $\begin{array}{l}\text { Mejorar la administración académica: las tutorías se realizan en algunas oportunidades } \\
\text { sin preparación, los exámenes y las calificaciones de los trabajos y exámenes son a } \\
\text { veces confusos. Incluso los exámenes se realizan a veces en locaciones que no permiten } \\
\text { la concentración. }\end{array}$ \\
\hline 3. & $\begin{array}{l}\text { Mayor eficiencia en homologaciones. Afectan a quienes vienen de otras instituciones } \\
\text { o carreras aún dentro de la unAD. }\end{array}$ \\
\hline 4. & Realizar buena planeación académica y respetar cronogramas y organización. \\
\hline 5. & $\begin{array}{l}\text { Seleccionar mejor el personal que atiende en la parte administrativa, que la } \\
\text { capaciten en atención al público o a estudiantes. }\end{array}$ \\
\hline 6. & $\begin{array}{l}\text { Realizar a tiempo la entrega de usuarios y contraseñas a los estudiantes, para } \\
\text { facilitar el normal desarrollo de los cursos. }\end{array}$ \\
\hline 7. & $\begin{array}{l}\text { Seguir, en la práctica, la metodología que se dice se va a manejar. Si se escoge un } \\
\text { programa virtual, es porque es el que más se adapta a las necesidades y limitaciones. } \\
\text { Y se espera que esa sea la metodología que se trabaje y no que haya que hacer } \\
\text { actividades presenciales obligatorias. }\end{array}$ \\
\hline 8. & $\begin{array}{l}\text { El modelo es correcto, pero la plataforma tiene deficiencias: debiera tener un } \\
\text { entorno más amigable. }\end{array}$ \\
\hline
\end{tabular}




\begin{tabular}{|c|c|}
\hline 9. & $\begin{array}{l}\text { Tener disponibles y actualizados los contenidos de cada materia o módulo para bajarlos } \\
\text { de la plataforma y no tener que leerlos desde la misma, porque se pierde tiempo. }\end{array}$ \\
\hline 10. & $\begin{array}{l}\text { Esforzarse más en el desarrollo de competencias de análisis e interpretación } \\
\text { sobre las problemáticas sociales, económicas y políticas de la sociedad y en la } \\
\text { implantación exigente de habilidades. }\end{array}$ \\
\hline 11. & Que las tutorías tengan una mayor frecuencia (sean más seguidas). \\
\hline 12. & $\begin{array}{l}\text { No poner tantos trabajos en grupo, sobre todo en la metodología virtual, ya que si } \\
\text { se estudia en esta modalidad es porque no se dispone de tiempo para depender de } \\
\text { otras personas. }\end{array}$ \\
\hline 13. & $\begin{array}{l}\text { Reprogramar el trabajo en grupos colaborativos. Son demasiado pesados, sobre } \\
\text { todo si son con presencia física. Hay gran dificultad para los encuentros a fin de } \\
\text { realizar los trabajos en grupo. }\end{array}$ \\
\hline 14. & Dar más énfasis a ejercicios y trabajos individuales. \\
\hline 15. & $\begin{array}{l}\text { Mejorar la calidad de las Guías y de las actividades de evaluación tanto en } \\
\text { pertinencia, ortografía y presentación. }\end{array}$ \\
\hline 16. & $\begin{array}{l}\text { Desarrollar contenidos más completos para lograr mayor aprovechamiento en la } \\
\text { metodología a distancia. }\end{array}$ \\
\hline 17. & $\begin{array}{l}\text { Mejor la organización de los semestres y de las materias, para que el estudio no } \\
\text { resulte tan pesado. }\end{array}$ \\
\hline 18. & $\begin{array}{l}\text { La norma de tener } 5 \text { materias obligatorias como mínimo, hace difícil el estudio por } \\
\text { cuestiones de tiempo, así como de pago. }\end{array}$ \\
\hline 19. & $\begin{array}{l}\text { Estudiar virtualmente, en una plataforma, implica mayor inversión en recursos } \\
\text { (computador en casa), esfuerzo, tiempo, etc. Por tanto, "por norma" debería tener } \\
\text { mayor atención, tutoría y flexibilidad. }\end{array}$ \\
\hline 20. & $\begin{array}{l}\text { Mayor flexibilidad en las fechas de evaluación y en prueba nacional. En ésta } \\
\text { debiera haber parciales, no evaluar el } 100 \% \text {. }\end{array}$ \\
\hline 21. & Revisar periódicamente los programas que se ofrecen. \\
\hline 22. & Ajustar los horarios de tutorías a la disponibilidad de los estudiantes. \\
\hline 23. & $\begin{array}{l}\text { Dar mayor énfasis en los temas propios de cada programa o carrera seleccionada y } \\
\text { menos en otras materias. }\end{array}$ \\
\hline 24. & Los contenidos de una materia en la metodología a distancia deben ser más específicos. \\
\hline 25. & $\begin{array}{l}\text { Tener grupos más reducidos de estudiantes por tutor, para que presten mejor } \\
\text { colaboración a resolver las deficiencias del estudiante. }\end{array}$ \\
\hline 26. & Intensificar la relación académica presencial (física o virtual) con el docente. \\
\hline 27. & $\begin{array}{l}\text { Hay temas, materias o programas que no debieran realizarse de manera virtual } \\
\text { (ejemplo, en agropecuarias), ya que es muy complicado adquirir por ese medio las } \\
\text { competencias y el perfil práctico que requieren. }\end{array}$ \\
\hline 28. & En la formación a distancia se requiere mayor flexibilidad. \\
\hline
\end{tabular}




\begin{tabular}{|c|c|}
\hline 29. & $\begin{array}{l}\text { La cantidad de trabajos para realizar en un semestre es excesiva. Mejorar la } \\
\text { planificación y coordinación entre los trabajos de las diversas materias en un } \\
\text { semestre. La mayoría de los estudiantes son trabajadores. }\end{array}$ \\
\hline 30. & $\begin{array}{l}\text { La opción de educación a distancia cubre en gran manera el nicho de personas que están } \\
\text { laborando, no programar los exámenes finales entre semana y en horarios laborales. }\end{array}$ \\
\hline 31. & Evitar desorden en las notas. \\
\hline 32. & Hacer cumplir el manual de docentes y el de estudiantes. \\
\hline 33. & Los créditos inter-semestrales de recuperación, prolongan innecesariamente las carreras. \\
\hline 34. & Los cambios de pensum son necesarios, pero afectan al estudiante. \\
\hline 35. & $\begin{array}{l}\text { No es posible que en aprendizaje (particularmente de inglés) no haya una } \\
\text { intercomunicación más intensa. }\end{array}$ \\
\hline 36. & Mejorar la atención en las aulas informáticas. \\
\hline 37. & Mejorar el manejo de atención al público y a los estudiantes. \\
\hline 38. & Mejorar las condiciones de planta física. \\
\hline 39. & Mejorar disponibilidad de equipos. \\
\hline 40. & No ocultar, sino mejorar las falencias administrativas. \\
\hline 41. & $\begin{array}{l}\text { Dar opciones de reintegro y facilidades de pago a los estudiantes que desean seguir } \\
\text { estudiando. }\end{array}$ \\
\hline \multicolumn{2}{|c|}{ Sugerencias sobre tutoría y tutores: } \\
\hline 1. & $\begin{array}{l}\text { Mayor énfasis en la preparación en metodología de los docentes: hay } \\
\text { inconsistencias. }\end{array}$ \\
\hline 2. & Cumplir la programación de las tutorías. \\
\hline 3. & Mejorar la dedicación de los tutores y asistir los horarios programados. \\
\hline 4. & $\begin{array}{l}\text { En la modalidad a distancia es cierto que debe haber más compromiso del estudiante, } \\
\text { pero cuando hay dudas debe haber alguien que pueda resolverlas. }\end{array}$ \\
\hline 5. & $\begin{array}{l}\text { En la etapa inicial, por lo menos durante los dos primeros semestres, debe haber } \\
\text { mayor acompañamiento por parte de los tutores. }\end{array}$ \\
\hline 6. & Mayor preparación de los docentes/tutores. \\
\hline 7. & $\begin{array}{l}\text { Mayor apoyo: estudiantes por sí solos no son capaces de entender la totalidad de } \\
\text { la información. }\end{array}$ \\
\hline 8. & Mayor claridad en las explicaciones de tutores. \\
\hline 9. & Resolver dudas de los estudiantes, sobre todo en los foros. \\
\hline 10. & $\begin{array}{l}\text { La función de una verdadera tutoría es resolver las dudas que se generan y apoyar } \\
\text { al estudiante en las partes débiles de su auto- aprendizaje a distancia. }\end{array}$ \\
\hline 11. & Mayor acompañamiento al estudiante en proceso de adquisición de conocimiento \\
\hline 12. & Mejorar los mecanismos de comunicación entre docentes y alumnos. \\
\hline 13. & Más encuentros con tutores (físicos o virtuales) y mayor apoyo de ellos. \\
\hline
\end{tabular}




\begin{tabular}{|c|c|}
\hline 14. & $\begin{array}{l}\text { Introducir las videoconferencias con tutores, especialmente para resolver dudas y } \\
\text { preguntas. }\end{array}$ \\
\hline 15. & $\begin{array}{l}\text { Mejor la escogencia de tutores. En algunos no hay vocación, metodología, ni } \\
\text { seriedad, sobre todo con trabajos de los estudiantes: se envían por correo electrónico, } \\
\text { los extravían y al final resulta que no se enviaron. }\end{array}$ \\
\hline 16. & Mayor interactividad en proceso de formación. \\
\hline 17. & $\begin{array}{l}\text { Debe haber "demos" y ejemplos prácticos en las materias, especialmente de } \\
\text { ciencias (física y química). }\end{array}$ \\
\hline 18. & Cumplimiento en la programación de tutorías, evaluaciones, visitas a fincas, etc. \\
\hline 19. & $\begin{array}{l}\text { No asignar horarios de tutoría en horas de oficina, ya que buena parte de los } \\
\text { estudiantes trabaja. }\end{array}$ \\
\hline 20. & Garantizar un proceso de atención más eficaz y humano. \\
\hline 21. & $\begin{array}{l}\text { Mejorar el volumen de estudiantes asignados a cada tutor. Esto posiblemente incide } \\
\text { para que los tutores no sean más receptivos y comunicativos con los estudiantes y } \\
\text { que la tutoría sea más efectiva. }\end{array}$ \\
\hline 22. & Dedicar parte del tiempo de tutoría a contestar preguntas. \\
\hline 23. & $\begin{array}{l}\text { En la virtualidad los tutores y directores deben priorizar la solución de } \\
\text { dificultades. }\end{array}$ \\
\hline 24. & Mayor seguimiento de los tutores en el desempeño del estudiante. \\
\hline 25. & Que cuando se inicie el semestre todo esté listo: eso es programación y orden. \\
\hline 26. & $\begin{array}{l}\text { Mayor seriedad en las notas (se entregan unas a los estudiantes, y en ocasiones } \\
\text { aparecen otras) }\end{array}$ \\
\hline 27. & $\begin{array}{l}\text { Mayor personalización en el trato a los estudiantes. Los estudiantes merecen y } \\
\text { requieren un trato más cálido y personal. }\end{array}$ \\
\hline 28. & $\begin{array}{l}\text { Dar mayor retroalimentación en las evaluaciones: eso ayuda al estudiante a entender } \\
\text { en qué se equivocó y qué corregir. }\end{array}$ \\
\hline 29. & $\begin{array}{l}\text { Hacer corrección de tareas a tiempo. Mayor oportunidad en la entrega de } \\
\text { evaluaciones y notas. }\end{array}$ \\
\hline 30. & $\begin{array}{l}\text { Por vivir muchos lejos de las ciudades donde hay CEADs, es muy difícil hacer } \\
\text { diligencias personalmente. Están las opciones de e-mail, la Internet, el teléfono, } \\
\text { etc. Debe darse mejor atención a estos medios para dar respuestas eficaces. }\end{array}$ \\
\hline 31. & $\begin{array}{l}\text { Mayor flexibilidad. Por ejemplo, al empezar un estudiante con algún retraso (lo que } \\
\text { es frecuente) es muy difícil que los tutores den oportunidades de ponerme al día } \\
\text { con los ejercicios, las evaluaciones y notas. }\end{array}$ \\
\hline 32. & $\begin{array}{l}\text { Disponer de un claro sistema de información, en especial en lo que se refiere a las } \\
\text { homologaciones, fechas, diligencias administrativas, programas económicos, etc. }\end{array}$ \\
\hline 33. & $\begin{array}{l}\text { Disponer de sistemas especializados de tutorías y administración académica para } \\
\text { estudiantes que viven fuera del país (sobre todo en países de mayor éxodo). }\end{array}$ \\
\hline
\end{tabular}




\section{Sobre el curso introductorio y la consejería:}

\begin{tabular}{|c|c|}
\hline 1. & $\begin{array}{l}\text { Es muy necesario el curso introductorio. (Para algunos, el curso introductorio es } \\
\text { excelente. Para otros el material de introducción es deficiente. Requiere cambios). }\end{array}$ \\
\hline 2. & $\begin{array}{l}\text { Para mejorar el proceso de inducción hay que hacer mayor profundización en } \\
\text { práctica de la metodología de estudio a distancia. Se requiere que la inducción sea } \\
\text { práctica, no solo teoría. }\end{array}$ \\
\hline 3. & La disciplina en la formación a distancia es vital. Insistir más en ella. \\
\hline 4. & $\begin{array}{l}\text { Más colaboración para aprender a manejar el sistema de educación a distancia, ya } \\
\text { que se proviene de un sistema presencial y es difícil cambiar esa metodología. }\end{array}$ \\
\hline 5. & $\begin{array}{l}\text { Garantizar que el estudiante domine la metodología de aprendizaje autónomo. Eso } \\
\text { hace que no se "queme". }\end{array}$ \\
\hline 6. & $\begin{array}{l}\text { Mayor apoyo a los jóvenes (de 16-20 años) que escogen la metodología a distancia } \\
\text { y virtual, ya que carecen de experiencia profesional y disciplina. }\end{array}$ \\
\hline 7. & Mayor seguimiento a estudiantes de primeros semestres. \\
\hline 8. & $\begin{array}{l}\text { Más atención de los consejeros y tutores para guiar a los estudiantes en la } \\
\text { metodología a distancia desde el primer semestre, para que no se sientan tan solos } \\
\text { en el aprendizaje. }\end{array}$ \\
\hline 9. & $\begin{array}{l}\text { Concientizar al estudiante sobre la importancia de hacer una buena escogencia de } \\
\text { la carrera. Sería muy importante que antes de que cada persona escoja una carrera, } \\
\text { se le preste el servicio de test u otras formas de orientación vocacional. }\end{array}$ \\
\hline 10. & $\begin{array}{l}\text { Mejores sistemas de comunicación y orientación para solucionar las inquietudes y } \\
\text { solicitudes de los estudiantes. No siempre se sabe claramente a quién acudir. }\end{array}$ \\
\hline 11. & Generar un ambiente acogedor. \\
\hline 12. & $\begin{array}{l}\text { Estudiar psicológicamente a cada estudiante acerca de sus perfiles y } \\
\text { problemáticas. }\end{array}$ \\
\hline 13. & $\begin{array}{l}\text { Seguimiento inmediato al estudiante cuando se note su ausencia. Hacer mayores } \\
\text { esfuerzos antes de que se retire. }\end{array}$ \\
\hline 14. & $\begin{array}{l}\text { Persistencia en el seguimiento a estudiantes por diferentes medios antes del } \\
\text { retiro: teléfono, correo electrónico, conferencias/encuentros virtuales, visitas } \\
\text { domiciliarias, etc. }\end{array}$ \\
\hline 15. & $\begin{array}{l}\text { Mejorar el sistema de apoyo al estudiante: Al terminar materias, no se recibe } \\
\text { orientación sobre pasos a seguir. Sobre todo, si se está fuera del país. Ofrecer } \\
\text { mayor orientación al respecto. }\end{array}$ \\
\hline \multicolumn{2}{|c|}{ Sobre metodología y tecnología: } \\
\hline 1. & Evitar la improvisación. \\
\hline 2. & Mejor los vacíos y la presentación de los materiales. \\
\hline 3. & $\begin{array}{l}\text { Mejorar tanto el proceso de ejecución de la metodología a distancia tradicional } \\
\text { como la virtual. }\end{array}$ \\
\hline
\end{tabular}




\begin{tabular}{|c|c|}
\hline 4. & $\begin{array}{l}\text { Las tutorías presenciales (con presencia física o virtual) deben ser más continuas, } \\
\text { ya que esto permite mejorar los aprendizajes. }\end{array}$ \\
\hline 5. & $\begin{array}{l}\text { Mejorar la inter-acción para no sentirse actuando sólo con una máquina. Es } \\
\text { frustrante. }\end{array}$ \\
\hline 6. & Usar plataforma virtual es una opción excelente. \\
\hline 7. & $\begin{array}{l}\text { Mayor preocupación por "nivelar" conocimientos e integrar los estudiantes. En } \\
\text { ocasiones, hay estudiantes que vienen masivamente de instituciones con mayor } \\
\text { preparación (Ej.: del SENA) y no se nivelan los conocimientos de los otros, lo que } \\
\text { impide la integración. }\end{array}$ \\
\hline 8. & $\begin{array}{l}\text { El problema no es la metodología a distancia o virtual. Es la práctica pedagógica } \\
\text { en una u otra metodología. }\end{array}$ \\
\hline 9. & Mejorar el funcionamiento de la plataforma para evitar problemas. \\
\hline 10. & $\begin{array}{l}\text { Mayor claridad en la información, en especial en lo que se refiere a las } \\
\text { homologaciones. }\end{array}$ \\
\hline 11. & $\begin{array}{l}\text { Mejorar, en los cursos virtuales, la inflexibilidad de las fechas indicadas en la agenda } \\
\text { para colgar los trabajos. En algunos casos se cambian, presentándose sorpresas al } \\
\text { tratar de subir un trabajo. La percepción del estudiante es que se cae en una trampa } \\
\text { al inscribir cursos y no tener la oportunidad de cursarlos. }\end{array}$ \\
\hline \multicolumn{2}{|c|}{ Sobre costos y financiación: } \\
\hline 1. & Dar facilidades de pago. \\
\hline 2. & Reducir costos (otras instituciones son más baratas). \\
\hline 3. & $\begin{array}{l}\text { Aumentar plazos de financiación o dar la posibilidad de cancelarlos en varios } \\
\text { contados (por mes o en varios plazos). }\end{array}$ \\
\hline 4. & $\begin{array}{l}\text { Mayor ofrecimiento de créditos por parte de la Institución y con adecuada } \\
\text { financiación, diferentes a los del ICETEX (que tienen muchos trámites). }\end{array}$ \\
\hline \multicolumn{2}{|c|}{ Sobre laboratorios: } \\
\hline 1. & $\begin{array}{l}\text { Mejorar los laboratorios específicos para las carreras, particularmente en Ingeniería } \\
\text { de sistemas. }\end{array}$ \\
\hline 2. & No crear falsas expectativas con los laboratorios. \\
\hline \multicolumn{2}{|c|}{ Sobre disponibilidad de tiempo: } \\
\hline 1. & $\begin{array}{l}\text { Ese es un gran problema, sobre todo para la realización de los trabajos colectivos. } \\
\text { Se sugiere repensar esta práctica. }\end{array}$ \\
\hline
\end{tabular}

\section{A MANERA DE CONCLUSIÓN}

Son varias y de diverso orden las consideraciones que podrían extraerse de este interesante ejercicio investigativo. Sin duda, la primera hace relación al elevado número de estudiantes que abandona sus estudios, hecho que implica un gran "desperdicio" de recursos y esfuerzos públicos y privados, amén de los sinsabores y frustraciones que ello implica para las personas involucradas. 
Sin embargo, las cifras muestran que las estrategias puestas en marcha por la institución durante el último período han comenzado a reducir el fenómeno de la deserción en la UNAD. Y, si bien no existen aún evaluaciones de impacto, puesto que de acuerdo con las estadísticas anotadas, el punto de inflexión (año 2004) se encuentra aún muy próximo, se estaría evidenciando un descenso significativo, que parece correlacionar con las estrategias y medidas adoptadas con la creación institucional del Sistema Nacional de Consejería. De hecho, a partir de ese año las cifras de abandono estudiantil disminuyen en forma sostenida, y el ejercicio con la cohorte 2004-I, lo corrobora plenamente. Con todo, de acuerdo con las cifras y, en especial con las respuestas dadas a la encuesta por quienes vivieron la dolorosa situación de retirarse sin culminar sus propósitos $\mathrm{y}$, que como tal son actores de primer orden, no cabe duda que hay que redoblar los esfuerzos por encontrar nuevas estrategias y eficientes mecanismos para poder disminuir en forma significativa la deserción actual. En cualquier época, pero especialmente en la actualidad cuando el conocimiento es factor fundamental de desarrollo, nada justifica que una persona que ha mostrado interés por formarse a nivel superior, tenga que abandonar ese propósito.

Un segundo hecho relevante es que, para las cohortes del actual período institucional, no se presentan diferencias significativas con el resto del país, donde prima la educación presencial, y ello no obstante las características y condiciones desventajosas del estudiantado de la UNAD, que ha encontrado quizás en la modalidad a distancia y virtual su única oportunidad de desarrollo. Este hecho puede ser objeto de múltiples y positivas lecturas que ameritan más profundos análisis y, sobre todo, determinaciones.

De una parte, las estrategias y mecanismos introducidos a partir de 2004 que buscan cubrir de forma integral los diferentes factores asociados con el abandono estudiantil (en particular, el mejoramiento de las condiciones académicas de ingreso, el fortalecimiento del modelo pedagógico, los avances en materia de medios y mediaciones pedagógicas y la cualificación del cuerpo académico) parecen estar dando un resultado positivo. Sin embargo, parece igualmente evidente que habría que mejorar diversos aspectos en la programación y administración académica, en las inter-relaciones tutor/estudiante, así como en el pleno dominio de la metodología a distancia y virtual por parte de los estudiantes.

De otra parte, el ingreso a la digitalidad o a la denominada "educación virtual", si bien evidencia haber causado algunos inconvenientes en el caso de la UNAD, contrario a ser un factor causante o asociado a la deserción, evidencia haber colaborado, junto con otros factores, en la disminución de las diferencias entre la educación a distancia y la presencial. Estas diferencias tienden a diluirse, también en el campo de la deserción. Sin embargo, si bien la virtualidad brinda múltiples facilidades sobre todo a los trabajadores que desean continuar estudiando, debe realizar una práctica de flexibilidad, que es el pleno significado de la "apertura", que atienda específicamente a sus características, limitaciones y necesidades. Al respecto, no cabe duda de que se debería continuar haciéndo renovados esfuerzos. 
Ahora bien, de acuerdo con los resultados de la encuesta, parece necesario combatir entre una serie de diversas "situaciones", unas pocas prioritarias que, según los desertores, afectan los estudios a distancia y virtual e inciden directamente sobre la deserción.

En primer lugar, la metodología a distancia y virtual exige una extremadamente cuidadosa planificación y programación académicas. Cualquier falencia o debilidad al respecto, por pequeña que parezca, incide negativamente no sólo sobre los aprendizajes, sino sobre la deserción. En segundo lugar, aunque hayan pasado algunas décadas de introducción de esta metodología, siempre será indispensable, con cada cohorte, una muy profunda y práctica inducción, hasta garantizarse que se ha interiorizado y se domina plenamente la metodología. No lograrlo incide igualmente de forma directa sobre el rendimiento académico y, finalmente, sobre el abandono de los estudios. En tercer lugar, pero quizás es el aspecto más sentido por quienes vivieron la dolorosa experiencia de abandonar sus estudios, la metodología a distancia y virtual exige una preparación y dedicación especial del personal docente (directores, tutores y consejeros) y sobre todo una intensa intercomunicación con los estudiantes. Si bien es cierto que estas metodologías exigen una mayor actividad y esfuerzo en el aprendizaje autónomo por parte del estudiante, eso no significa que ellos deban estar, y menos aún, sentirse solos, ni que deje de requerirse la presencia permanentemente de alguien atento y capaz de resolver las dudas e inquietudes de los estudiantes, máxime cuando éstos presentan debilidades propias de quien ha dejado un tiempo de estudiar, no ha tenido los mejores rendimientos académicos o no tiene las mejores competencias académicas. Esa disponibilidad permanente de asistencia es, sin lugar a dudas, la función central de directores, tutores y consejeros (si bien por razones de organización, puede haber entre ellos, cierta división coordinada de funciones). Así se manifiesta claramente en la encuesta.

$\mathrm{Y}$ aquí, de acuerdo con lo expresado en la encuesta, caben algunas precisiones. La asincronicidad en el estudio a distancia y virtual es -sin lugar a dudas- una ventaja, ya que el estudiante estudia y se ejercita en su tiempo disponible. Sin embargo, es altamente recomendable y -sin duda- necesario, que en la interacción con el estudiante haya igualmente programación de momentos de intercomunicación sincrónica, en tiempo real. En la actualidad las TICs existentes permiten disponer no sólo de correo electrónico, chats y foros asincrónicos, sino de audio y video-conferencias sincrónicas, en tiempo real, que permiten un contacto más cercano tutor-estudiantes para brindar asistencia y acompañamiento, con presencia no física, sino virtual. Hacer uso de estos avances de la interactividad, típica de la denominada web 2, son una posibilidad y un requerimiento manifiesto de los estudiantes.

Finalmente, y para sólo hacer mención de unos pocos elementos, si bien la deserción hace fundamentalmente relación a la cobertura o aspectos cuantitativos de la educación, la no evidencia (al menos durante los últimos años) de diferencias significativas entre las modalidades educativas (como parece pudo haberse dado en el período inicial), debería posicionar aún más a la modalidad de educación a distancia y virtual, ya que esta metodología parece estar realmente asociada a la requerida inclusión, equidad y justicia social. Así lo indican los perfiles diferenciales entre los estudiantes de uno y otro tipo de educación. Sin 
lugar a dudas, al menos en el caso de la UNAD, son los estudiantes con mayores limitaciones socio-económicas y académicas quienes están haciendo uso de la educación a distancia y virtual. Como tal, estas metodologías se perfilan como el medio privilegiado de acceso a la educación superior para dichos grupos, y en consecuencia, como el medio más adecuado para lograr incidir masivamente en el mejoramiento de los niveles de educación y en el aprovechamiento del conocimiento para elevar la productividad y competitividad, sin las endémicas exclusiones. En otras palabras, podría afirmarse que la educación a distancia y virtual se perfila como el mecanismo privilegiado para acceder masivamente a la sociedad del conocimiento.

Sólo se requerirían dos requisitos: de una parte, disponer del necesario "alistamiento digital" (e-readiness) que, como se ha demostrado, es fundamentalmente un asunto de decisión política; y, de otra, lograr una "buena práctica" de dichas metodologías, es decir alcanzar un cambio en ciertos paradigmas "tradicionales" que se han venido afincando igualmente en esta metodología y que afectan su calidad.

La necesidad de investigación cada vez más específica y profunda sobre la práctica pedagógica en esta modalidad es uno de los primeros pasos en el amplio camino de alcanzar los desarrollos requeridos y deseables. La UNAD ha comenzado a recorrerlos. Empero, es urgente contar con la información estadística y análisis a nivel del país. Al respecto, una gran ayuda sería que el Sistema de Prevención y Análisis de la Deserción en las Instituciones de Educación Superior -SPADIES- del Ministerio de Educación Nacional, afinara y acelerara sus esfuerzos también en la modalidad a distancia y virtual.

\section{REFERENCIAS BIBLIOGRÁFICAS}

CASTAÑO, E., GALLÓN, S, GÓMEZ, K. y VÁSQUEZ, J., Deserción estudiantil universitaria: una aplicación de modelos de duración. Lecturas de Economía, 60, 41-65, 2004.

CEDE (2007). Estudio sobre deserción en las instituciones de educación superior en Colombia. Universidad de los Andes (sin fecha, documento electrónico).

GAVIRIA, MARIO ALBERTO. Capital humano, complementariedades factoriales y crecimiento económico en Colombia. En: Ensayos de economía, ISSN 0121-117X, Vol. 15, No . 27, 2005.

GIRÓN, L. E. y GONZÁLEZ, D. Determinantes del rendimiento académico y la deserción estudiantil, en el programa de economía de la Pontificia Universidad Javeriana de Cali. Economía, Gestión y Desarrollo, 3, 173-201, 2005.

ICFES y UNIVERSIDAD NACIONAL DE COLOMBIA, Estudio de la deserción estudiantil en la educación superior en Colombia. Bogotá: ICFES, 2002.

MINISTERIO DE EDUCACIÓN NACIONAL. Deserción Estudiantil en la Educación Superior colombiana. Elementos para su diagnóstico y tratamiento. Bogotá: MEN, 2008. 
MINISTERIO DE EDUCACIÓN NACIONAL. Análisis de determinantes de la deserción en la educación superior colombiana con base en el SPADIES. Primera parte: Factores Socioeconómicos. Factores Académicos e institucionales. Bogotá, 2008.

SPADY, W. Dropout from higher education: an interdisciplinary review and synthesis. Interchange, 2, 64-85, 1970.

TINTO, V. Dropout from higher education: a theoretical synthesis of recent research. Review of Educational Research, 45, 89-125, 1975.

TINTO, V. Definir la deserción una cuestión de perspectiva. Revista Educación superior, $71,1989$.

TINTO, V. Dropout from higher education: a theoretical synthesis of recent research. Review of Educational Research, 45, 89-125, 1975. 